\title{
SUSCEPTIBILIDADE DE ALGUMAS PRAGAS A DOIS NOVOS GRUPOS DE INSETICIDAS
}

\author{
JOSE ALBERTO DONGO CAMPOS \\ Engenheiro Agrônomo
}

Orientador: Prof. Dr. OCTÁVIO NAKANO

Dissertação apresentada à Escola Superior de Agricultura "Luiz de Queiroz", da Universidade de São Paulo, para obtenção do Título de Mestre em Ciências Biológicas, Área de Concentração: Entomologia.

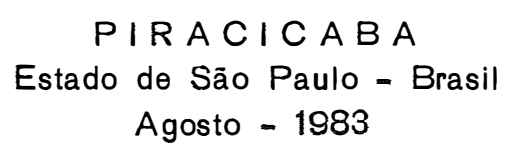


ii.

\author{
Aos, meus pais, \\ - meu agradecimento \\ eterno.
}

A Elizete, minha esposa, Betinho, Graziela, Natacha, meus filhos com amor.

DEDICO. 


\section{AGRADECIMENTOS}

Ao Prof. Dr. Octávio Nakano, pela sua valiosa orientação, es timulo e amizade.

$\bar{A}$ todos os professores do Departamento de Entomologia da ESALQ pelos ensinamentos recebidos e pela amizade e consideração dispensadas.

$\bar{A}$ Engo Agro Sonia Komatsu pela valiosa ajuda nos testes de laboratório.

Aos estagiários do Departamento de Entomologia da ESALQ pela colaboração.

Ao Sr. Sergio Yamane e irmãos pela ajuda na captura dos inse tos.

Ao Prof. Dr. Evôneo Berti Filho, pela versão do resumo para o inglês.

A Dra. Marineia Haddad, pesquisadora da EMBRAPA pela valiosa ajuda na análise estatística.

A Elizete, pelo incentivo e ajuda constante.

Aos meus sogros Herminio e Virginia pela valiosa ajuda. 


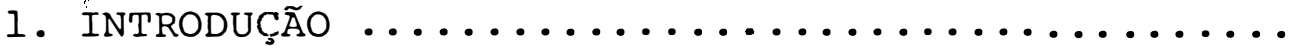

2. REVISÃo de LITERATURA $\ldots \ldots \ldots \ldots \ldots \ldots \ldots$

3. MATERIAL E METODO $\ldots \ldots \ldots \ldots \ldots \ldots \ldots \ldots \ldots$

4. RESUltados E DiscUSSÃo $\ldots \ldots \ldots \ldots \ldots \ldots \ldots$

4.1. Experimentos com Euschistus heros .........

4.2. Experimentos com Alabama argillacea .......

4.3. Experimentos com Heliothis virescens ......

5. CONCLUSÕES $\ldots \ldots \ldots \ldots \ldots \ldots \ldots \ldots \ldots \ldots \ldots \ldots \ldots \ldots$

6. Literatura CItAdA $\ldots \ldots \ldots \ldots \ldots \ldots \ldots \ldots \ldots$ 

e mortos (M) durante 5 horas, tratados com deltamethrina (10 g.ia/ha) com e sem óleo em dois diferentes ambientes térmicos. Piracicaba, sp - $1983 \ldots \ldots \ldots \ldots \ldots \ldots \ldots$

Análise de variância dos dados apresentados na tabela 1 transformados em $\sqrt{x+0,5}$. Delineamento experimental blocos ao acaso, com esquema fatorial $2 \times 2 \times 5$. Piracicaba, SP-

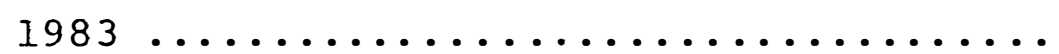

Análise de variância dos dados apresentados na tabela 1 transformados em $\sqrt{x+0,5}$. para interação c/s óleo $x$ tempo. Piracica

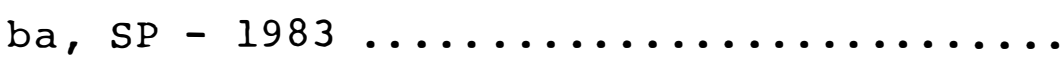

Análise de variância para os dados apresen tados na tabela 1 transformados em $\sqrt{\mathrm{x}+0,5}$ para a interação tempo $x$ c/s óleo ........

Teste Tukey para a variável tempo dos dados apresentados na tabela 1 e transformados em $\sqrt{\mathrm{x}+0,5}$. Piracicaba-SP, $1983 \ldots \ldots$

Teste Tukey para a interação tempo $x$ s / óleo dos dados apresentados na tabela 1 e transformados em $\sqrt{x+0,5} \ldots \ldots \ldots \ldots \ldots$ 

e mortos (M) durante 5 horas, tratados com cypermethrina $(40 \mathrm{~g}$.ia/ha) com e sem óleo em 2 diferentes ambientes térmicos. Piraci

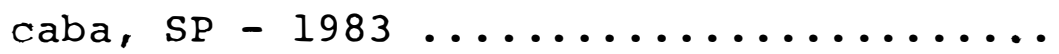

Análise de variância dos dados apresentados na tabela 7 transformados em $\sqrt{x+0}, 5$. Delineamento experimental blocos ao acaso com esquema fatorial $2 \times 2 \times 5$. Piracicaba, SP 1983

Teste Tukey para a variável tempo dos dados apresentados na tabela 7 e transforma dos em $\sqrt{x+0,5}$ Piracicaba, SP - $1983 \ldots$

Teste Tukey para a interação tempo $x$ tempe ratura (208C) dos dados apresentados na ta bela 7 e transformados em $\sqrt{x+0,5}$. Piracicaba, sP - $1983 \ldots \ldots \ldots \ldots \ldots \ldots \ldots \ldots \ldots \ldots \ldots \ldots \ldots \ldots$

11 Teste Tukey para a interação tempo $\mathbf{x}$ s/ óleo dos dados apresentados na tabela 7 e transformados em $\sqrt{x+0,5}$. Piracicaba, SP-

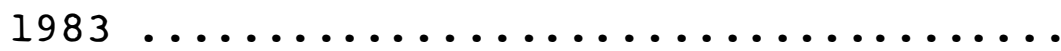

12 Nümeros de percevejos de $E$. heros vivos (V) e mortos (M) durante 5 horas, tratados com avermectina (18 g.ia/ha) com e semóleo em dois diferentes ambientes térmicos. Piraci caba, sP - $1983 \ldots \ldots \ldots \ldots \ldots \ldots \ldots \ldots$ 
vii.

TABELA NO

Página

13 Número de lagartas de A. argillacea vivas (V) e mortas (M) durante 5 horas, tratadas com deltamethrina ( $5 \mathrm{~g} \cdot \mathrm{ia} / \mathrm{ha}$ ) com e sem óleo em dois diferentes ambientes térmicos. Piracicaba, SP - $1983 \ldots \ldots \ldots \ldots \ldots \ldots \ldots \ldots$

14 Análise de variância dos dados apresentados na tabela 13 transformados em $\sqrt{x+0,5}$. Delineamento experimental blocos ao acaso, com esquema fatorial $2 \times 2 \times 5$. Piracicaba, SP

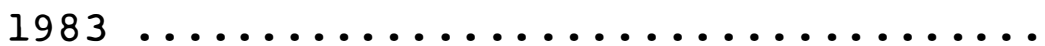

15 Análise de variância dos dados apresentados na tabela 13 transformados em $\sqrt{\mathrm{x}+0,5}$ para a interação adição de óleo x tempo. Piraci caba, sp - $1983 \ldots \ldots \ldots \ldots \ldots \ldots \ldots \ldots$

16 Número de lagartas de A. argillacea vivas (V) e mortas (M) durante 5 horas, tratadas com cypermethrina $(20 \mathrm{~g} . \mathrm{ia} / \mathrm{ha})$ com e sem óleo em dois diferentes ambientes térmi cos. Piracicaba, SP - $1983 \ldots \ldots \ldots \ldots \ldots \ldots$

17 Análise de variância dos dados apresentados na tabela 16 transformados em $\sqrt{\mathrm{x}+0,5}$. Delineamento experimental blocos ao acaso com esquema fatorial $2 \times 2 \times 5$. Piracicaba, SP

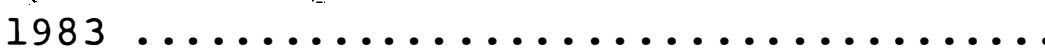

18 Análise de regressão para a variável tempo dos dados apresentados na tabela 16 transformados em $\sqrt{\mathrm{x}+0,5}$. Piracicaba,sP-1983 .. 
viii.

Número de lagartas de A. argillacea vivas (V) e mortas (M) durante 5 horas, tratadas com avermectina (18 g.ia/ha) com e sem óleo em dois diferentes ambientes térmicos. Piracicaba, sP - $1983 \ldots \ldots \ldots \ldots \ldots \ldots$

Número de lagartas de $H$. virescens vivas (V) e mortas (M) durante 5 horas, tratadas com deltamethrina em duas doses com e sem óleo em três diferentes ambientes térmicos.

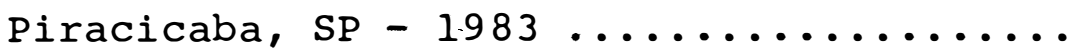

21 Análise de variância dos dados apresentados na tabela 20 , transformados em $\sqrt{\mathrm{x}+0,5}$ para a variável temperatura, delineamento inteiramente casualizado. Piracicaba, SP 1983

Análise de variância dos dados apresentados na tabela 20 transformados em $\sqrt{\mathbf{x}+0,5}$ para a variável dosagem, delineamento inteiramente casualizado. Piracicaba, SP -

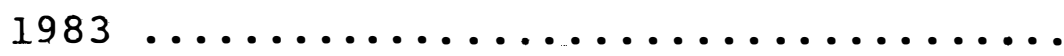

23 Números de lagartas de $H$. virescens vivas (V) e mortas (M) durante 5 horas, tratadas com cypermethrina $(40 \mathrm{~g} \cdot \mathrm{ia} / \mathrm{ha})$ com e sem ôleo a três diferentes ambientes térmicos. Piracicaba, SP - $1983 \ldots \ldots \ldots \ldots \ldots \ldots$ 
Análise de variância dos dados apresentados na tabela 23, transformados em $\sqrt{x+0,5}$ para a variável adição de óleo a 32:C. Delineamento inteiramente casualizado. Piracicaba, SP - $1983 \ldots \ldots \ldots \ldots \ldots \ldots \ldots$

Análise de variância dos dados apresentados na tabela 23 transformados em $\sqrt{x+0,5}$ para a variável temperatura. Delineamento inteiramente casualizado. Piracicaba, SP -

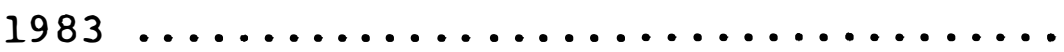

Números de $H$. virescens vivas (V) e mortas (M) durante 5 horas, tratadas com avermecti na (18 g.ia/ha) com e sem óleo a três diferentes ambientes térmicos. Piracicaba

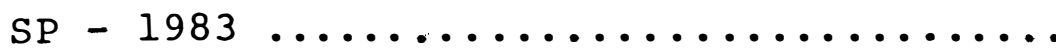

27 Análise de variância dos dados apresentados na tabela 26 transformados em $\sqrt{x+0,5}$ para a variável adição de óleo a 25:C. Delineamento inteiramente casualizado. Pira-

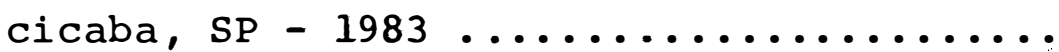

Análise de variância dos dados apresentados na tabela 26 transformados em $\sqrt{x+0,5}$ para a variável temperatura. Delineamento inteiramente casualizado. Piracicaba, SP -

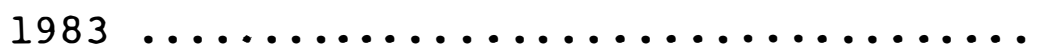




\section{LISTA DE FIGURAS}

FIGURA NO

Página

1 Micropipeta, modelo "pipetman", utilizada para aplicações tópicas nos insetos duran te os ensaios, Piracicaba, 1983 ........

Modo de aplicação tópica em percevejos (E. heros nos tarsos dianteiros, Piracicaba,

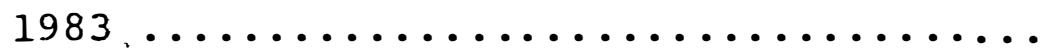


xi.

\title{
SUSCEPTIBILIDADE DE ALGUMAS PRAGAS A DOIS NOVOS GRUPOS DE INSETICIDAS
}

\author{
José Alberto Dongo Campos \\ Autor \\ Prof. Dr. Octávio Nakano \\ Orientador
}

RESUMO

O presente trabalho trata da toxicidade de dois diferentes grupos de inseticidas, utilizados em três pragas chaves de duas culturas de importância econômica. Os testes fo ram conduzidos no laboratório do Departamento de Entomologia da Escola Superior de Agricultura "Luiz de Queiroz"-USP, em Piracicaba, Estado de São Paulo, no período de dezembro de 1982 a abril de 1983.

Os insetos apōs serem submetidos a aplicações tópicas com deltamethrina $2,5 \% \mathrm{CE}$, cypermethrina $40 \% \mathrm{CE}$ (gr $\underline{\text { u }}$ po piretróide) e avermectina 1,8\% C.E. (grupo lactona), macro ciclica, misturados ou não com óleo vegetal, foram colocados sob duas temperaturas ambientais (20-320) para avaliação da influência dessas condições em relação ao efeito tóxico.

A análise dos resultados mostrou que para Heliothis virescens (Fabr., 1781) nãohouve diferença significativa namortalidade pa ra as temperaturas de 20 e $320 \mathrm{C}$ com cypermethrina. As doses 
utilizadas de deltamethrina $(6,0$ e $10 \mathrm{~g} \cdot \mathrm{i} . \mathrm{a} . / \mathrm{ha})$ se comporta ram de modo semelhante e a adição de óleo vegetal a 32:C não melhorou a eficiência da cypermethrina

Para Euschistus heros (Fabr., 1794) houve maior morta lidadecom deltamethrina na primeira hora após a aplicação tópica. $A$ adição de óleo vegetal a esse inseticida teve efeito negati vo. Utilizando cypermethrina, a adição de óleo vegetal, também mostrou efeito negativo durante a primeira hora da avalia ção a 20:C.

Em Alabama argillacea (Hueb., 1818) a adição de óleo vecetal àdeltamethrina teve efeito positivo sobre a mortalidade ape nas na primeira hora. Com cypermethrina, a mortalidade das lagartas não sofreu influência quando se adicionou óleo vegetal às temperaturas utilizadas; porēm, houve maior mortalidade durante a primeira hora após a aplicação tópica.

Para as pragas em questão não houve diferença significativa na mortalidade dos insetos nas temperaturas de 20 e 32 :C quando se empregou avermectina, bem como, a adição de óleo vegetal não causou efeito positivo na eficiên cia do produto. 


\author{
SUSCETIBILITY OF SOME PESTS TO TWO NEW \\ GROUPS OF INSECTICIDES
}

Author: José Alberto Dongo Campos

Adviser: Prof. Dr. Octávio Nakano

SUMMARY

The present study deals with the toxicity of two different classes of insecticides on three key pests of two crops of economic importance. The tests were conducted in the laboratory of the Department of Entomology Escola Superior de Agricultura "Luiz de Queiroz" at Piracicaba, São Paulo from dezember 1982 to April of 1983.

After the insects were treated with topical doses of $2.5 \%$ EC deltamethrin, $40 \%$ EC cypermethrin class (pirethroid) and $1.8 \% \mathrm{EC}$ avermectin (class lactone macrocyclic), they were held at two different temperatures todetemine the role of temperature on toxicity of these three insecticides. All insecticides were tested with and without the addition of vegetable oil.

The results showed that there was no significant difference in mortality to Heliothis virescens (Fabr., larvae when cypermethrin was applied at both 20 and 328C. The dosage of deltamethrin used, 6.0 and $10.0 \mathrm{~g}$. active ingredient/ 
xiv.

ha, perfomed similarly. The addition of vegetable oil at 328C did not improve the efficacy of cypermethrin.

With respect to Euschistus heros (Fabr., 1794) the greatest mortality with deltamethrin ocurred between the first and the second hour after the application. The addition of vegetable oil to deltamethrin had a negative effect. The addition of vegetable oil to cypermethrin also had a negative effect during the first hour after application at $208 \mathrm{C}$. With respect to Alabama argillacea (Hueb., 1818), the addition of vegetable oil to deltamethrin only had a positive effect on mortality only during the first hour; with cypermethrin, addition of vegetable oil had no effect on mortality at the temperature tested. However, the greatest mortality occurred during the first hour topical application. There was no significant difference in mortality of all pests at all temperatures with and without the addition of vegetable oil when avermectin was used. 


\section{INTRODUÇÃO}

A grande quantidade de pragas existentes na la voura algodoeira, sempre exigiu um volume considerável de defensivos com numerosas aplicações, com a finalidade de evitar os prejuízos causados por elas.

A despeito desse volume e dos diversos grupos de inseticidas existentes, variando inclusive quanto a sua for mulação e o modo de aplicação, poucos são os estudos que visam o conhecimento da eficiêncía dos mesmos sobre as pragas, em ãiferentes condições climāticas, dessas, a temperatura parece influir de maneira significativa, seja pela sua oscila ção frequente, dentro de uma determinada região, seja pela variação existente entre uma região e outra, mas todas produtoras dessa malvácea.

Com frequência são observados trabalhos que mos tram eficiência variável de um mesmo inseticida sem que se possa atribuir a eles uma causa dessa variação.

A literatura existente, tem mostrado que os in 
seticidas, modernos ou não, podem ser alterados em seu modo de ação, variando-se a temperatura do meio ambiente onde são aplicados, afetando as pragas em maior ou menor grau. Em geral, tais produtos se correlacionam positivamente com as temperaturas elevadas.

Muitas vezes, a temperatura influi diretamente sobre o organismo dos insetos, permitindo em função de seu me tabolismo uma maior ou menor absorção do tóxico, pela ação de contato. Mas a atividade dos inseticidas pode também estar relacionada com o tipo de formulação, aquosa ou oleosa, sendo estas igualmente afetadas pela alteração da temperatura do ambiente.

Recentemente surgiram outros grupos de inseticidas, considerados mais sensíveis aos efeitos já citados. En tre eles, destacam-se os piretróides e a complexidade dessas combinações se acentua quando se sabe que essas substâncias a fetam em maior grau, determinados grupos de insetos, Indepen dentemente dos fatores climáticos.

Com base nessas considerações, procurou-se estabelecer a presente pesquisa, com o intuito de conseguir subsídios que possam esclarecer os problemas existentes, contribuindo para uma melhor adequação dos defensivos nas lavouras de algodão e soja. 


\section{REVISÃO DE LITERATURA}

$$
\text { Diversos são os trabalhós mostrando a influên- }
$$
cia da temperatura na toxicidade dos inseticidas.

$$
\text { LINDQUIST et al. (1945), em trabalhos feitos }
$$
com DDT em moscas domésticas, notaram que quando expostas con tinuamente a 709F, elas morriam mais rapidamente do que, a temperaturas superiores.

$$
\text { POTTER e GILLHAM (1946), utilizando Tribolium }
$$

castaneum Herbst eaplicando seis inseticidas de contato, com dosagens determinadas, concluiram que na temperatura ambiente não houve diferença significativa na mortalidade dos insetos. porém, quando os besouros foram colocados após pulverização sob condições frias, as piretrinas e DDT mostraram-se mais 
eficientes. Em condições mais frias, a nicotina foi muito mais tóxica. Submetidos a condições quentes o óleo de petrō leo mostrou-se mais tóxico.

HOFFMAN (1949), estudou o efeito de choque de três inseticidas em moscas domésticas expostas a duas diferentes temperaturas (70 e 909F), mantendo os insetos por períodos pré-determinados de 1 a 20 minutos à ação dessas temperaturas. DDT, DDD e Metoxicloro tiveram efeito de choque su perior a $709 \mathrm{~F}$ do que a 909F, causando consequentemente maior mortalidade. Porém, com heptacloro, parathion, clordane, diel drin e toxafeno, ocorreu o contrário.

PRADHAN (1949), citando trabalhos realizados

por POTTER e GILLHAM (1946), mostrou a importância dos diferentes efeitos da temperatura sobre a mortalidade de insetos submetidos à ação de inseticidas. Referindo-se a ação por contato e ingestão, constatou alta mortalidade a baixa temperatura. Mas, com relação a fumigantes a mortalidade foi maior a altas temperaturas.

GUTHRIE (1950), realizou estudos sobre o efeito da temperatura na toxicidade de cinco inseticidas orgânicos. Com aplicações tópicas em Blatta germanica, constatou que DDT, piretro e lindane deram melhor resultado a baixas temperaturas e dieldrin e aldrin foram mais eficientes a altas temperaturas.

BLUM e KEARNS (1956), realizando aplicações tó picas com piretro em Periplaneta americana, mostraram um coe- 
ficiente negativo de temperatura entre 15 e $359 \mathrm{C}$ sendo que a 159C O LD 50 para piretro foi 1,0 ug e a $359 \mathrm{C}$ o $\mathrm{DL}_{50}$ foi de 6 ug.

PRADHAN e RANGARAO (1957), examinaram os efeitos' de cinco temperaturas utilizando Tribolium castaneum. Os insetos foram pulverizados com 5 ou 6 formulações diferentes de inseticidas. Soluções emulsionáveis de DDT, BHC, tô xafeno, clordane e parathion foram utilizadas. A mortalidade diminuiu com a elevação da temperatura de $149 \mathrm{C}$ para 2.39C e au mentou quando a temperatura se elevou de $309 \mathrm{C}$ para $409 \mathrm{C}$.

DAS e NEEDHAM (1960), estudaram os efeitos da mudança de temperatura (15-289C) sobre a toxicidade do DDT em larvas de Aedes aegypti e determinaram que quando as larvas eram expostas a DDT $(0,02 \mathrm{ppm})$ havia um aumento da toxicidade ao ser elevada a temperatura. Porém, quando as la vas eram deixadas em suspensões de DDT, a um aumento de temperatura, correspondia um decréscimo de ação tóxica, isto a baixas concentrações $(0,0002 \mathrm{ppm})$. A altas concentrações $(0,1$ - 0,2 ppm), a ação tóxica foi maior em larvas submetidasa bai xa temperatura.

Os autores afirmam que, ao mudar a temperatura de alta para baixa, aumenta a paralisia da larva, que é recuperada quando a temperatura muda de baixa para alta.

VAIL et alii (1967), mostraram trabalhos feitos em 1961/63, estudando o controle de Brevicoryne brassicae em brássicas, e de Myzus persicae em pêssego. Os autores ve- 
rificaram que quando as temperaturas máximas eram inferiores a 709C, parathion, endosulfan, naled e gusathion não proporcionaram um resultado satisfatório.

GIRISH e RAI (1966), fizeram testes com larvas

de Trogoderma granarium criadas a 359C e pulverizadas com piretrinas. As larvas apōs 4, 8 e 12 dias foram transferidas para tubos de ensaio a 35 e 159C. Aos 12 dias foi feita avaliação encontrando-se uma maior mortalidade em insetos mantidos a 35.C do que a 159. .

ABO-ELGHAR et alii. (1970), estudando os efeitos da temperatura na toxicidade de dicofol, tetradifon e amidithion em ovos e adultos do ácaro Cenopalpus pulcher, mos traram que a toxicidade de dicofol e tetradifon estava correlacionada negativamente com a temperatura para ovos, enquanto que amidithion foi correlacionado positivamente. Os adultos após o tratamento foram colocados em temperaturas de 20 , 30 e 359. Concluiram que a toxicidade de tetradifon e amidithion foi positiva, enquanto que para dicofol, foi negativa.

ATWAL et alii. (1969), realizando estudos em la boratório, mostraram que besouros de Sitophilus oruzae mantidos em placas de petri, préviamente impregnadas com BHC, foram mais facilmente mortos a temperaturas de 25,30 e 359C do que a 209C. Isto pode ser resultado da intensa atividade dos insetos, quando a temperatura aumenta, consequentemente en iram em contato com maior quantidade de inseticida. FAHMY et alij (1979), fazendo testes de foto e 
termodecomposição em laboratório, determinaram que os piretróides fenvalerato e cypermethrina sofreram rápida fotodecomposição quando comparados com triazophos (hostathion). Nenhum

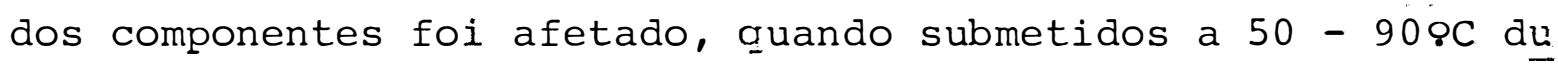
rante 90 minutos.

KUSHWAHA e SHARMA (1968), estudaram O efeito da temperatura, umidade e inseticidas em populações de Orthop tera, Coleoptera, Hemiptera, Diptera e Hymenoptera em cultura de alfafa e, concluiram que as populações de insetos estão intimamente ligadas à temperatura e umidade. Ambas tiveram efeito significante em Diptera tanto separadas como combinadas. Para as outras ordens, nenhum efeito foi observado. No teste de controle com cinco inseticidas, aldrin foi o mais eficiente seguido de malathion, endrin, BHC e DDT.

TEOTIA e PANDEY (1967), fizeram testes com inseticidas de contato: DDVP (diclorvos), malathion, dieldrin e carbaryl em adultos de Tribolium castaneum com base na sua $\mathrm{LC}_{50}$, utilizando 2 níveis de temperatura $(27$ e $35 \% \mathrm{C})$ com $75 \%$ de umidade relativa e 2 níves de unidade relativa (70 e 90\%) a 27\%c. Amortalidade após 24 horas, mostrou que os 3 primeiros inseticidas, foram melhor a altas temperaturas e o último foi melhor a mais baixa. Diclorvos, dieldrin e carbaryl, foram mais efi cientes à umidade mais alta. Para malathion ocorreu o inverso.

ABULLAH (1967), afirma que a temperatura é uma das variāveis gue influem na eficiência dos in- 
seticidas. Diz ainda que o coeficiente de temperatura de um inseticida, seja positivo ou negativo, depende da constitui ção química do próprio inseticida, do seu modo de ação e da espécie do inseto.

NORMENT e CHAMBERS (1970), estudaram as relaÇões de organofosforados em bicudo (Anthonomus grandis) e mos traram um coeficiente positivo de temperatura com parathion metílico e malathion. As toxicidades de gusathion e EPN, foram bastante diminuidas a 109C, enquanto que o desfolhante DEF, mostrou toxicidade a 329C. De modo geral, a mortalidade dos insetos expostos a 328C e mantidos a $109 \mathrm{C}$ foi duas vezes maior que daqueles expostos e mantidos a 108C. Isto sugere que, a temperatura pode afetar a toxicidade e a taxa de absorção do inseticida pelo inseto.

HARRIS (1971), conduziu trabalhos visando determinar a influência da temperatura sobre a atividade biológica do solo, utilizando Acheta pensylvanicus a 15, 21, 27, e 339C. Estas temperaturas não afetaram a toxicidade do aldrin e heptacloro, mas apresentaram um coeficiente negativo. CHALFANT (1972), estudando o efeito da tempera tura após tratamento das folhas com diversos inseticidas e acaricidas em Trichoplusia ni, constatou que: methomỵl não foi afetado pela temperatura. A diminuição de 329C paral09C, resultou na perda de toxicidade de uma e meia vezes do monitor, três vezes do mevinphos e parathion metílico, dez vezes com endosulfan e vinte vezes com monocrotophos. Realizando 
aplicações tópicas, o mevinphos não foi afetado por temperatu彑 ras acima de 109C. Naled resultou na perda de toxicidade de duas vezes, três vezes com methomyl e monocrotophos, quatro e meia vezes com monitor e vinte e seis vezes com parathion metílico.

DE VRIES e GEORGHIOU (1978), estudaram a influência da temperatura, após tratamento com diversos inseticidas em Musca domestica; constataram que a toxicidade do dimetoato, parathion e isolan, não foi afetada pela temperatura entre 15 e 25 c. Porém, o bioresmethrin e lindane, foram altamente tóxicos a 15.C.

MAY (1980) expondo o crisomelideo Leptinotarsa decemlineata a temperaturas diferentes às do meio ambiente observou que, se submetidos a temperaturas acima do normal, os insetos aparentemente modificavam a temperatura do corpo procurando alimentos em lugares ensolarados a baixas temperaturas, ou movimentando-se para a sombra, quando a temperatura am biente era alta.

EL-TANTAWY et alii (1980), estudaram o índice de penetração de cinco inseticidas através de aplicações tópi cas e concluíram que o resultado na ordem do mais rápido para o mais lento foi: Clorpiriphos > cypermethrina > endosulfan > Du-pont 1462 > endrin. Observações químicas e biológicas, mos traram que existe correlação entre a dose e. o índice de penetração do inseticida.

EL-OKDA et alii (1978), testando 4 piretróides 
sintéticos, 8 organofosforados, 2 clorados e 1 carbamato, com a finalidade de determinar o efeito de algumas misturas concluirram que os piretróides foram os produtos mais tóxicos. Dos 4 piretróides, a cypermetrina e o fenvalerato foram os mais antagônicos quando combinados com outros inseticidas. OTSLIND et alii (1979), realizando trabalhos com Tribolium confusum expostos a $10 \mathrm{ppm}$ de avermectin (lac tona) determinaram que após 14 dias, 86 a 96\% dos besouros morreram comparados com 26\% da testemunha. Foram testados 4 frações diferentes de avermectin, sendo que todas elas causaram a morte de todos os insetos 28 dias após, ençuanto que 66\% da testemunha permaneciam vivos. O malathion foi usado como padrão, tendo sido mais potente, com uma atividade similar a $10 \mathrm{ppm}$ do avermectin ou menos.

PUTTER et alii (1981), mostraram que o avermec tin é uma lactona, derivada do Streptomyces avermitilis, tendo mostrado em testes de laboratório, um alto poder inseticida contra vários artrópodos, incluindo ácaros, lepidópteros, coleópteros,' afídeos e também contra alguns nematóides parasitos de plantas. Estudos mostram que o seu mecanismo de toxicidade é fundamentalmente diferente dos inseticidas sintéticos. 


\section{MATERIAL E METODOS}

Os experimentos foram conduzidos no laboratório do Departamento de Entomologia da Escola Superior de Agricultura "Luiz de Queiroz", em Piracicaba, Estado de São Pau10, no período de dezembro de 1982 a abriI de 1983.

Foram utilizados para este trabalho, 300 exemplares de Heliothis virescens (Fabr., 1781), na sua fase larval (do 29 ao 40 Instar), 600 exemplares de Alabama argillacea (Hueb., 1818) no 39 e 4o Instar larval e 600 exemplares de Enchistus heros (Fabr., 1794), na fase adulta, todos eles obtidos diretamente do campo em culturas de algodão e soja não pulverizadas com inseticidas, na região da Alta Mogiana (Guai ra, Jardinópolis, Ribeirão Preto). Os insetos foram transpor tados imediatamente após à captura, em gaiolas com farta alimentação, para o laboratório.

Aos insetos capturados, foram feitas aplicações tópicas, de 2 inseticidas do grupos dospiretróides: deltamethrina ecypermethrina, e um dogrupo das lactonas: avermectin, seguindo técnicas descritas por GUTRHIE (1950); BLUM e KEARNS (1956); CHAIFANT, (1972). 
Foi utilizado também um óleo vegetal de soja com emulsificante (Natur'l óleo), para medir o possível efeito sinérgico com os inseticidas utilizados, assim como, o efeito na velocidade de ação dos mesmos.

As dosagens utilizadas foram:

Deltamethrina 2,5\% para $H$. virescens: 6,0 e 10,0 g.i.a./ha C.E. para A. argillacea: 2,5 e 5,0 g.i.a./ha para E. heros: 10,0 g.i.a./ha

Cypermethrina $40 \%$ para H.virescens: $40 \mathrm{~g} . \mathrm{i} . \mathrm{a} . / \mathrm{ha}$ C.E. para A. argillacea: $20 \mathrm{~g} \cdot \mathrm{i} . \mathrm{a} . / \mathrm{ha}$ para E. heros: $40 \mathrm{~g} . \mathrm{i} . \mathrm{a} . / \mathrm{ha}$

Avermectin 1,8\%" paraH. virescens: $18 \mathrm{~g} . \mathrm{i} . \mathrm{a} . / \mathrm{ha}$ Solução. oleosa para E.heros: $18 \mathrm{~g} . \mathrm{i} . \mathrm{a} . / \mathrm{ha}$ para A. argillacea: 9,0 e 18 g.i.a./ha.

o volume de água utilizado em todos os casos foi de 240 litros por hectare.

A quantidade de óleo vegetal foi sempre de 2,5 1/ha.

As lagartas de H:virescens, foram colocadas indi vidualmente em tubos de ensaio para evitar $\circ$ canibalismo e, as lagartas de A. argillacea e os adultos de $E$. heros foram colocados em placas de petri em grupos de 20 e 10 exemplares respectivamente. 
Antes das aplicações tópicas, foi determinada a área de exposição do inseto ao tóxico, para posterior aplicação do inseticida em volume por área (l/ha). As lagartas fo ram agrupadas em cinco diferentes tamanhos, correspondendo una dose comum para cada grupo, como segue:

$$
\begin{aligned}
& \text { de } 0,38 \text { até } 0,59 \mathrm{~cm}^{2}-1,2 \mu l \\
& \text { de } 0,60 \text { até } 0,80 \mathrm{~cm}^{2}-1,7 \mu 1 \\
& \text { de } 0,81 \text { até } 1,01 \mathrm{~cm}^{2}-2,2 \mu 1 \\
& \text { de } 1,02 \text { até } 1,22 \mathrm{~cm}^{2}-2,7 \mu l \\
& \text { de } 1,23 \text { até } 1,43 \mathrm{~cm}^{2}-3,2 \mu l
\end{aligned}
$$

Para os adultos de $E$. heros foi estabelecida uma ărea padrão de $1 \mathrm{~cm}^{2}$, utilizando desta maneira, uma dosagem igual para todos os insetos.

Para as aplicações tópicas, foi utilizada uma micropipeta "pipetman" modelo p-20, com cåpacidade para pipetar de 0,1 até $20 \mu l$, fabricada pela RAININ INSTRUMENT; Co. Inc. (Fig. 1)

As aplicações tópicas nas lagartas foram fei tas à altura do 39 urômero, por serem os sensilos tricóides mais receptivos neste local (GALLO, et alii, 1978) e nos percevejos nos tarsos das patas dianteiras e médias (Fig. 2), por ser 0 lugar mais comum do senso gustativo nos insetos (GALLO, et alii, 1978).

Após a aplicação tópica, as larvas de H.virescens 


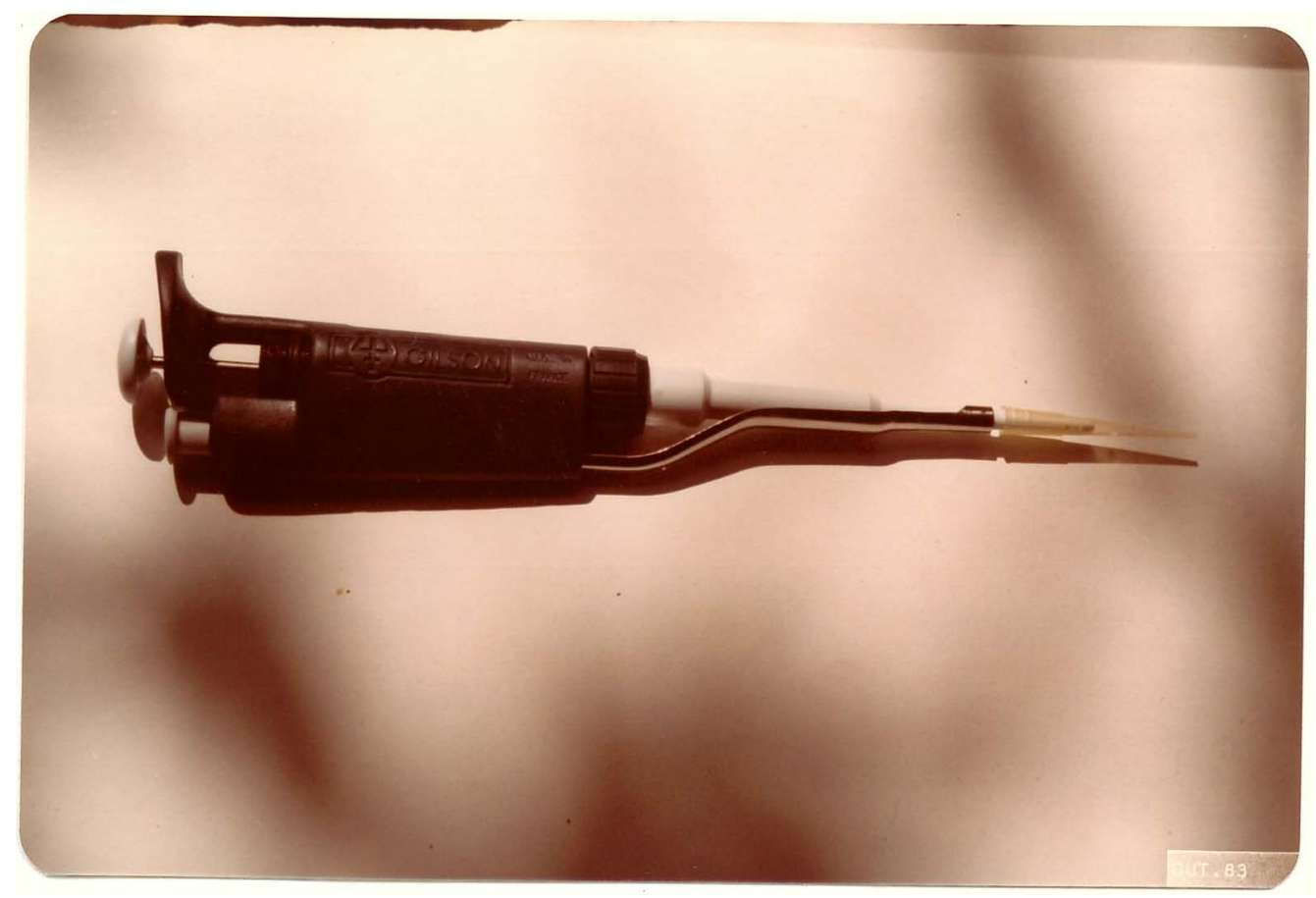

Figura 1. Micropipeta, modelo "pipetman", utilizada para apli cações tópicas nos insetos durante os ensaios, Pira cicaba, 1983.

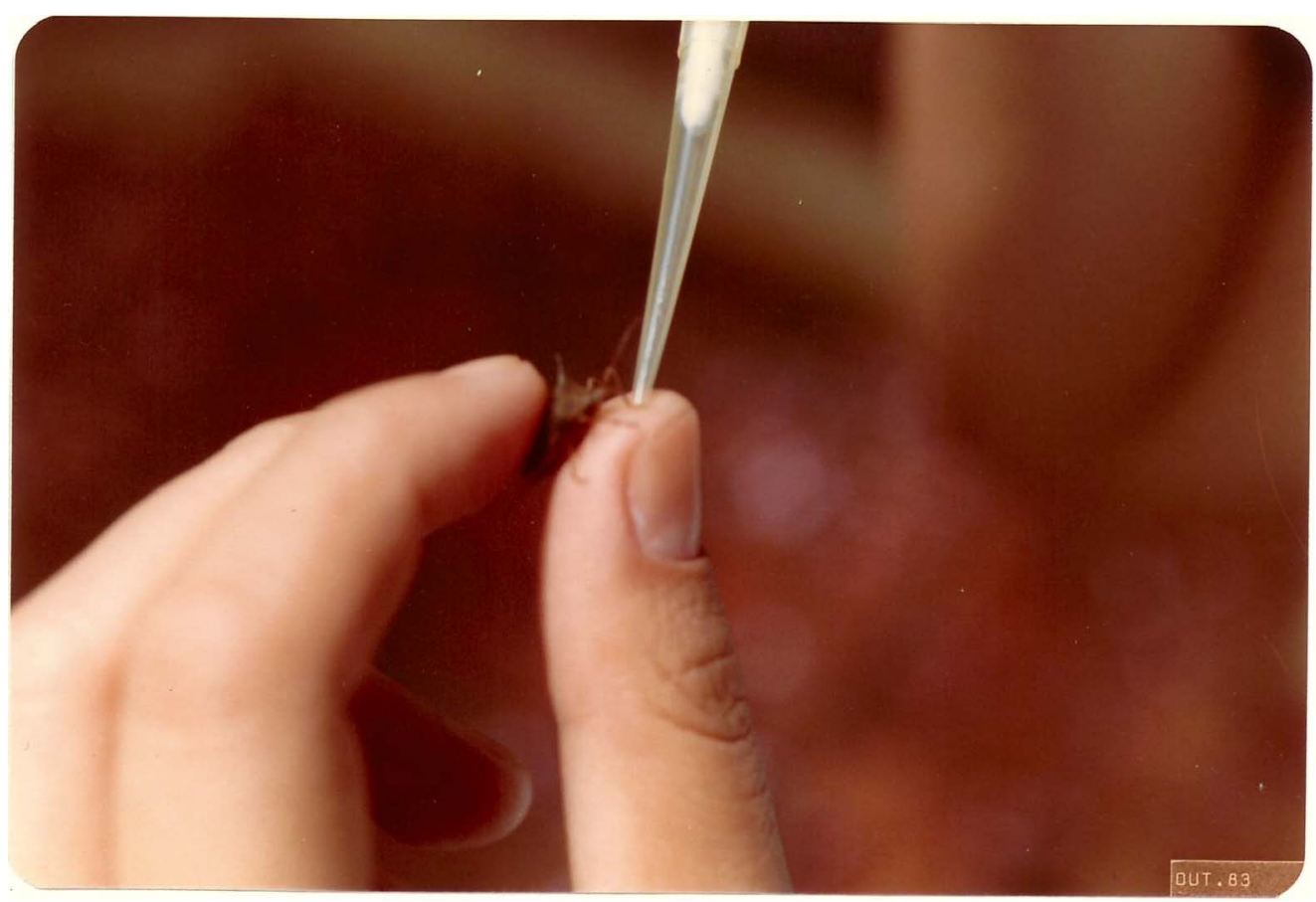

Figura 2. Modo de aplicação tópica em percevejos (E. heros) nos tarsos dianteiros, Piracicaba, 1983. 
foram colocadas em tubos de ensaio, sendo tampados com algodão para facilitar as trocas gasosas. Em cada tubo com a lagarta, foi colocado alimento (brotos do ponteiro e folhas tenras de plan tas de algodãol para assemelhar as condições de campo.

No caso das lagartas de A.argillacea,os indivíduos foram colocados em placas de petri com folhas de algodoeiro e no caso de E. heros colocaram-se vagens de soja. Em ambos os casos as placas de petri foram cobertas com panos de filó, para facilitar as trocas gasosas e a ação das temperaturas utilizadas.

As soluções foram preparadas em volume de 1,0 litro, e, após colocar uma alíquota num tubo de ensaio, se es perou que a espuma fosse eliminada, para introduzir a micropi peta e succionar o volume desejado para aplicação.

Os insetos submetidos a baixas temperaturas fo ram colocados previamente na geladeira a temperatura de $209 \mathrm{C}$ durante 15 minutos, para evitar a mudança térmica brusca.

Após aplicação tópica, os insetos foram coloca dos na geladeira, no caso de baixas temperaturas e em estufas para altas temperaturas. Em ambos os casos, foi colocado igual número de indivíduos sem aplicação, como testemunha.

Foram feitas 5 avaliações uma por hora. 0 critério para considerar o inseto morto, foi a completa paralização e ausência de movimentos mandibulares e locomotores. 
Cada avaliação foi feita à temperatura normal, (25:C) sendo os insetos logo após recolocados nas respectivas temperaturas em estudo.

Após finalizados os testes, tomou-se o cuidado de confirmar a morte do inseto, para evitar erros com paralisias que podem sugerir uma morte aparente dos mesmos (DAS e NEEDHAM, 1960), especialmente nos insetos submetidos às temperaturas baixas. 


\section{RESULTADOS E DISCUSSÃO}

\subsection{Experimentos com Euschistus heros.}

Observando a Tabela 1, pode-se notar que a atividade da deltamethrina é maior a baixa temperatura. Este resultado está de acordo com as observações feitas por GUTHRIE (1950) que fez aplicações em Blatta germanica e ainda BLUM e KEARNS (1956) que fizeram aplicações em Periplaneta americana. Porém, difere dos resultados obtidos por GIRISH e RAI (1966) que obtiveram maior mortalidade de Trogoderma granarium a 359C do que a 159C utilizando piretrinas.

A análise da variância das aplicações feitas com deltamethrina (Tabela 2) não mostraram diferenças signifi cativas entre as temperaturas utilizadas; porém, mostraram um efeito quadrático entre mortalidade e tempo após a aplicação. A análise da regressão para a variavièl tempo, mostrou que até a segunda hora houve maior mortalidade, se comparadas com as 
horas subsequentes (Tabela 3). A adição de óleo não acusou nos testes nenhuma melhora na atividade da deltamethrina.

A análise de variância. para cypermethrina mostrou que a adição de óleo teve efeito negativo na eficiência do produto (Tabelas 8 e 11). Este resultado está de acordo com trabalhos feitos por EL-OKDA et alii (1978) que mostraram um certo antagonismo da cypermethrina quando são adicionadas outras substâncias. A anālise de regressão mostrou que o pro duto foi mais eficiente durante a primeira hora após aplicação (Tabela 9) e a 20ọ de temperatura (Tabela 10).

Os dados com avermectina não foram analisados por serem muito escassos os resultados, indicando que as doses utilizadas não estavam de acordo ou, possivelmente devido ao efeito lento que este composto químico apresenta, fato já observado por PUTTER et alii (1981), quando demonstraram que - mecanismo de toxicidade deste produto é fundamentalmente di ferente dos inseticidas sintéticos.

\subsection{Experimentos com Alabama argillacea}

Nos testes com deltamethrina, apenas a variável adição de óleo foi significativa (Tabela 14) e a análise de regressão mostrou que a deltamethrina sem óleo, foi sig nificativamente mais eficiente durante a primeira hora de ação 
do tóxico (Tabela 15). Estas observações são semelhantes às da praga anteriormente discutida.

Utilizando cypermethrina, os dados mostraram que a mortalidade de A. argillacea independe da temperatura e da adição ou não de óleo vegetal (Tabela 17). Tais resultados podem indicar que a elevada suscetibilidade de A. argilla cea ao produto testado não tenha permitido a obtenção de dife renças por esses fatores. A análise de regressão mostrou que na primeira hora a atividade da cypermethrina é mais acentua da do que nas horas subsequentes (Tabela 18). Este fato foi constatado em relação à temperatura e a cypermethrina, fatoque já tinha sido observado por FARHMY et alii (1979) quando demonstra ram que não havia alteração quando este piretróide era submetido de 50 até 909 c durante 90 minutos.

Com referência à avermectina, não foram observados indícios que mostrem uma possivel alteração na ativida de do produto por causa do óleo adicionado.

4.3. Experimentos com Heliothis virescens.

Observando os dados da Tabela 20 verificou-se maior atividade da deltamethrina à temperatura mais elevada. Isto pode ser consequência do efeito fumigante deste piretróiāe já comentado por PRADHAM (1949) observando trabalhos realizados por Potter e Gillham (1946). Entretanto, na análi 
se de variância esta observação não foi confirmada (Tabela 21). Os testes com $H$. virescens não foram realizados seguindo um critério pré-determinado, devido a escassez de material o que impediu fazer repetições e consequentemente na análise de variância obteve-se coeficientes muito elevados.

No que se refere a dosagens, a Tabela 22 mostrou que não houve significância para as duas doses empregadas.

Utilizando cypermethrina não houve significân cia para as temperaturas testadas (Tabela 21) confirmando observações de FAHMY et alii (1979), já antes comentada.

o óleo vegetal à semelhança do ocorrido com as outras pragas em estudo, não mostrou vantagem nenhuma na mortalidade, quando adicionado aos inseticidas utilizados (Tabela 24). Observações feitas por EL-OKDA et alii (1978) demonstraram o antagonismo da cypermethrina quando misturado a outras substâncias.

Com referência a avermectina, a temperatura não interferiu na sua atividade (Tabela 28), nem a adição de óleo vegetal. (Tabela 27), embora os dados da Tabela 26 mostremque a 259C, H. virescens tenha sido mais sensivel. Com relação a este produto, pelas suas características químicas pareceser promissor especialmente à $H$. virescens que neste trabalho mos trou ser a praga mais sensível em relação às demais. 


\section{CONCLUSÕES}

Em vista dos resultados obtidos, pode-se concluir que:

1. Em rëlação ao efeito da temperatura, quando se emprega Euschistus heros, somente a cypermethrina mostra maior eficiência em temperaturas mais baixas. Para Heliothis virescens hà uma tendêncio para um melhor efeito da delta methrina quando a temperatura ambiental é elevada. No caso da Alabama argillacea não hā influência da variação da tem peratura aos inseticidas empregados, atribuído a uma maior susceptibilidade da espécie aos produtos. Avermectin por sua vez, não mostra diferença de eficiência, em diferentes temperaturas devido a baixa mortalidade dos insetos para o período testado.

2. No que diz respeito a adição de óleo vegetal aos inseticidas, a sua mistura com cypermethrina preju- 
dica o efeito tóxico para $E$. heros; entretanto, não se mostra vantajosa em relação às demais pragas e misturas com os outros inseticidas.

3. Em relação ao fator tempo, para $E$. heros, há um controle mais eficiente nas primeiras horas quando se aplica deltamethrina e cypermethrina a 209c. Para A. argillacea, deltamethrina e cypermethrina também são significa tivamente mais eficiente durante a primeira hora. 


\section{LITERATURA CITADA}

ABO-ELGHAR, M.R.; E.A. EL-BRADRY; S.M. HAJJAN; G.I. ZOHDY, 1970. Residual toxicity of three acaricides TC. no 1310 11. Review of Applied Entomology. 58 (1970) p. 467.

ABULLAH, M., 1967. Temperature and toxicity of inseticides Science e Industry 5 528-41. Review Applied Entomology $\underline{60}$ (1972) p.167.

ATWAL, A.S. E A.S. SIDHU, 1969. Effect of temperature and humidity on the toxicity of BHC aust. to sitophilus oryzal (L.) Indian J. Ent. 30 (1968) 266-71. Review of Applied Entomology 59 (1971) p. 575 .

BLUM, S.M. e C.W. KEARNS, 1956. Temperature and the action of Pyrethrun in the American cockroach. Journ. Econ. Ent. 49 (6) 862-65.

CHALFANT, B.R., 1972. Cabbage looper: Effect of temperature on toxicity of insecticides in the laboratory. Journal of Economic Entomology $66(2)$ : $339-41$. 
DAS, M. e P.H. NEEDHAM. Effect of time and temperature on toxicity of insecticides to insects Ann. Appl. Biol. 49: 32 38 .

DE VRIES, H.D. e G.P. GEORGHIOU, 1978. Influence of temperatü re on the toxicity of insecticides to susceptible and resistant House flies. Journ. Econ. Ent. $72(1):$ 48-50.

EL-OKDA, M.M.K.; K.E.D.A. YOUSSEF; M.A.S. ELEWA; M.R. ELrASSAR. M. R. Toxicity and join action for from sinthetic Pyre throids combined with certain insecticides against the cotton leaf-worm, Alexandria, Strains 514-522 (ENT, 10 ref) Agricultural research centr., Alexandria, Egypt. Review of Applied Entomology 68(1980) p. 550 .

EL-TANTAWY, M.A.; M.W. GUIRGUIS; A.A. BARAKAT; D.A. RAGHEB. The rate of penetration of some insecticides in spodoptera littoralis (Borsd) 429-436. [EN, 8 ref.] Department of plant protection. Faculty of Agriculture, Zayazig University. Egypt. Review of applied entomology 68 (1980), p. 548.

FAHMY, H.S.M.; A.A. BARAKAT; M.A. KAWOIL. The effect of exposure to UV-rays and temperature on SH-1467 (Sumicidin) and Triazophos 564-570 [EN, 7 ref.]. Faculty of Agriculture Cairo University. Egypt. Review of applied Entomology $\underline{68}(1980, \mathrm{p} .550$.

GALLO, D.; O. NAKANO; S. SILVEIRA NETO; R.P.L. de CARVALHO; G.C. de BATISTA; E. BERTI FILHO; J.R.P. PARRA; R.A. ZUCCHI e S.B. ALVES, 1978. Manual de Entomologia Agrícola. São Paulo, Ed. Agronômica Ceres, 53lp.

GIRISH, G.K. e B.K. RAI, 1966. Effect of temperature of the susceptibility of grubs of Trogoderma granarium Everts to pyrethrins. Indian J. Ent. 28: 401-04. Review Applied Entomology $\underline{56}$ $(1968)$, p.407. 
GUTHRIE, F.E., 1950. Effect of temperature on toxicity of Certain Organic Insecticides. Journ. Econ. Ent. 43 (4): $559-60$.

HARRIS, R.C. e S.A. TURNBULL, 1978. Laboratory studies on the contact toxicity and activity in soil of four pyrethoid insecticides. Can. Ent. 110: 285-88.

FARRIS, R.C., 1971. Influence of temperature on the biological activity of insecticides in soil. Journ. Econ. Ent. (5) : $1044-49$.

HOFFMAN, R.A. e A.W. LINDQUIST, 1949. Effect of temperature on knockdown and mortality of House Flies Exposed to residues of several Chloronated Hydrocarbon Insecticides. Jour. Econ. Ent. 42: $891-93$.

HASSAN, S.M.; M.R. ABO-ELGHAR; E.A. EL-BADRY; G.I. ZOHDY, 1970. Estudies on the chemical control of a fruit tree false spids mite Cenopalpus pulcher in the United Arab Republic. Relationships between temperature and toxicity of three acaricides. Jour. Econ. Ent. 63:

IORDANOU, N.T. E F.I. WATTERS, 1969. Temperature effect on the toxicity of five insecticides against five species of stored-products insects. Jour. Econ. Ent. 62: 130-35.

KUSHWAHA, K.S.; J.C. SHARMJ, 1968. Studes on seasonal inci dence of insects population in Lucerne effect of insecticides. Medras agric. J. 55: 265-72. Review of applied. Entomology 59(1971); p.27. 
LINDQUIST, W.A.; H.G. WILSON; H.O. SCHROEDER e A.H. MADDEN, 1945. Effect of temperatures on knokdown and kill of Hou seflies exposed to DDT. Jour. Econ. Ent. 38(2): 261-64.

MAY, M.I., 1982. Body tempertura and thermoregulation of the Colorado potato beetle, Leptinotarsa decemlineata (Jay). Entomologie Experimentalis et aplicata 3l(4): 413-20. Re view of Applied Entomology 70 (1982), p.716.

NORMENT, R.B. e H.W. CHAMBERS, 1970. Temperature relationships in organophosphorus poisoning in boll weevils. Jour. Econ. Ent. 63(2): 502-4.

OSLIND, D.A.; S. CIFELLI; R. LANG, 1979. Insecticidal activity of the anti-parasitic avermectin. Veterinary record 105 (8): 168. Review of Applied Entomology 68(1980), p.403.

PRADHAN, S. e P.V. RANGARAO, 1957. Effect of post temperature on insect resistance to insecticidal sprays. Bull. Ent. Res. $48: 261-74$.

PRADHAN, S:, 1949. Studies on the toxicity on insecticide films. Bull. Ent. Res. 40: 239-65.

POTTER, C. e E.;. GILLHAM, 1946. Effects of atmospheric environment, before and after treatment on the toxicity to insects of contact poisions. Ann. Appl. Biol. 33: 14259.

PUTTER, I.; J.G. MCCONNELL; F.A. PREISER; A.A. HAIDRI; S.S. RISTICH; R.A. DYBAS, 1981. Avermectin novel insecti cides, acaricides and nematicides from a soil microrganism. Experientia 37(9): 963-64. Review of Applied Entomology $\underline{70}(1982), \mathrm{p} .234$. 
TEOTIA, T.P.S.; K.K. PANDEY, 1967. The influence of tempera ture and humidity on the contact toxicity of some insecticide deposist to Tribolium castaneum Herbst. Bull Grain. Technol 5: 154-60.

VAIL, P.V.; M.W. STONE; J.C. MAITLEN; D.A. GEORGE e L.I. BUTLER, 1967. Performance of insecticides against cabbage and green persisrance of residues during cool weather. Jour. Econ. Ent. 60 (2): 537-40. 
$\underline{A} \underline{\mathrm{E}} \underline{\mathrm{N}} \underline{\mathrm{D}} \underline{\mathrm{C}} \underline{\mathrm{E}}$ 

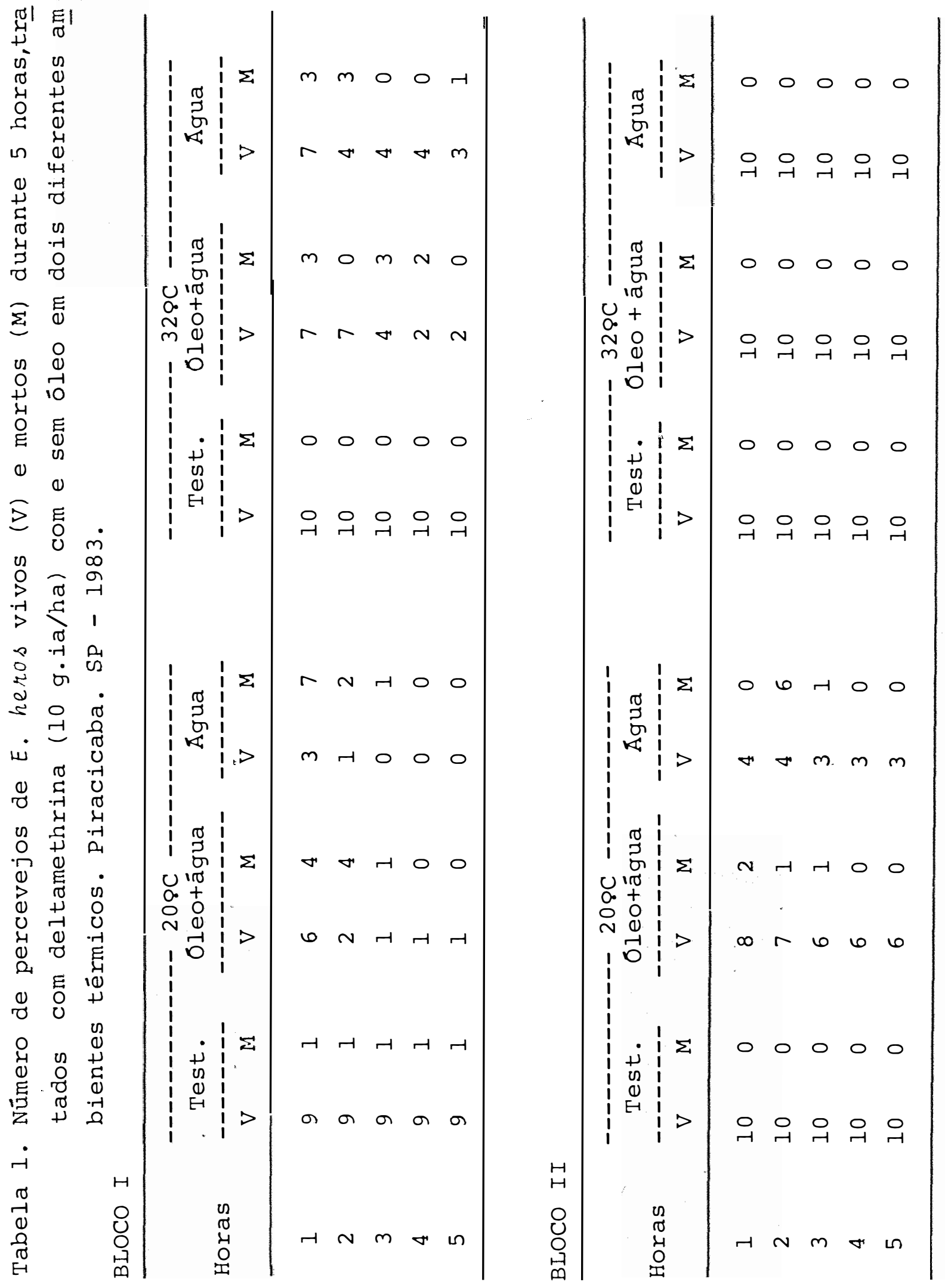
30.

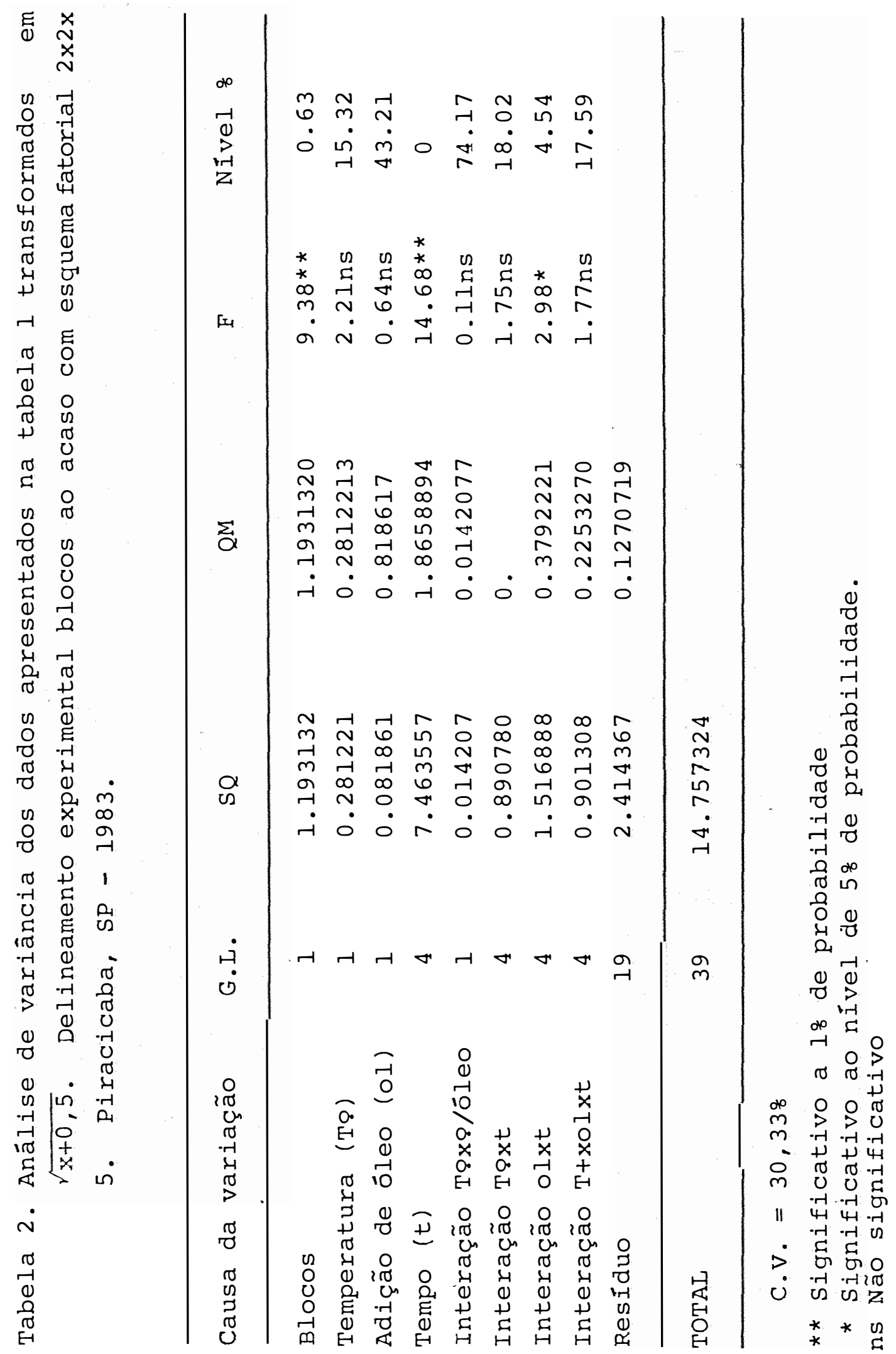


31.

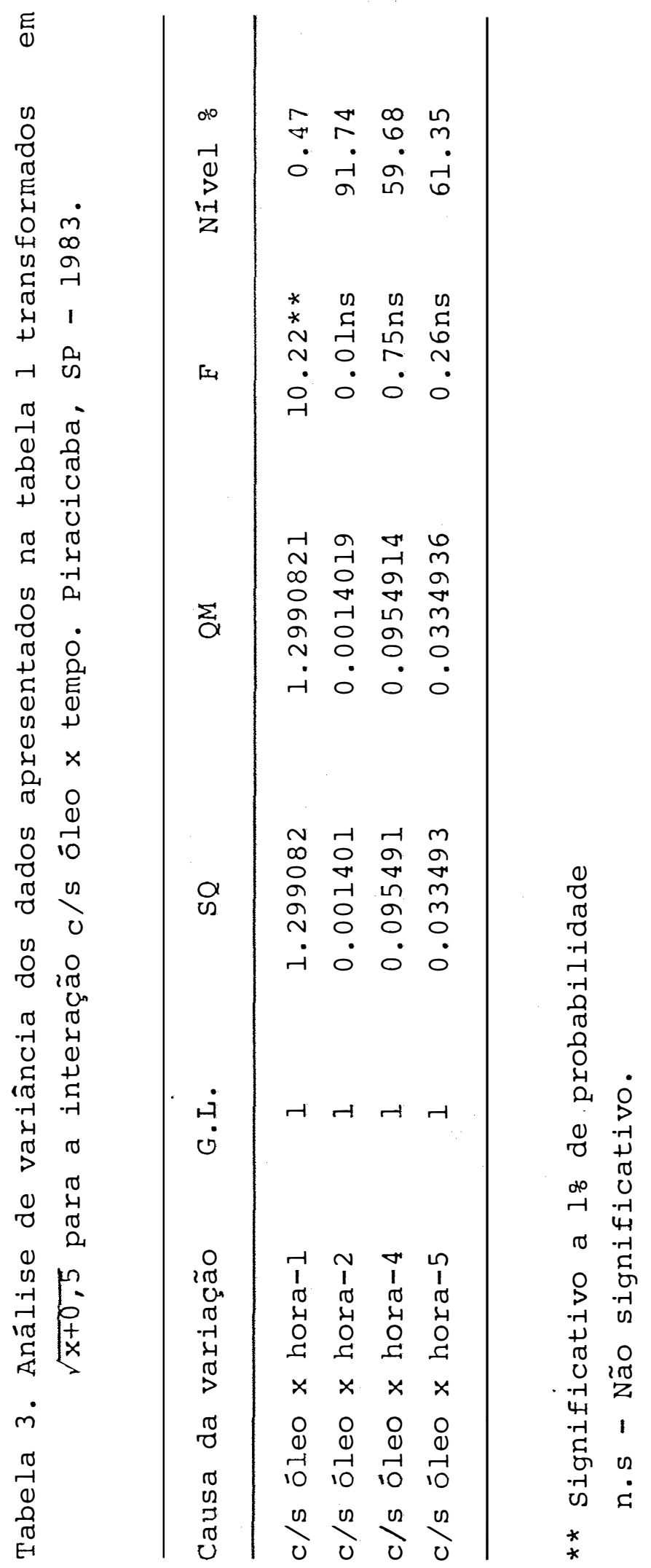




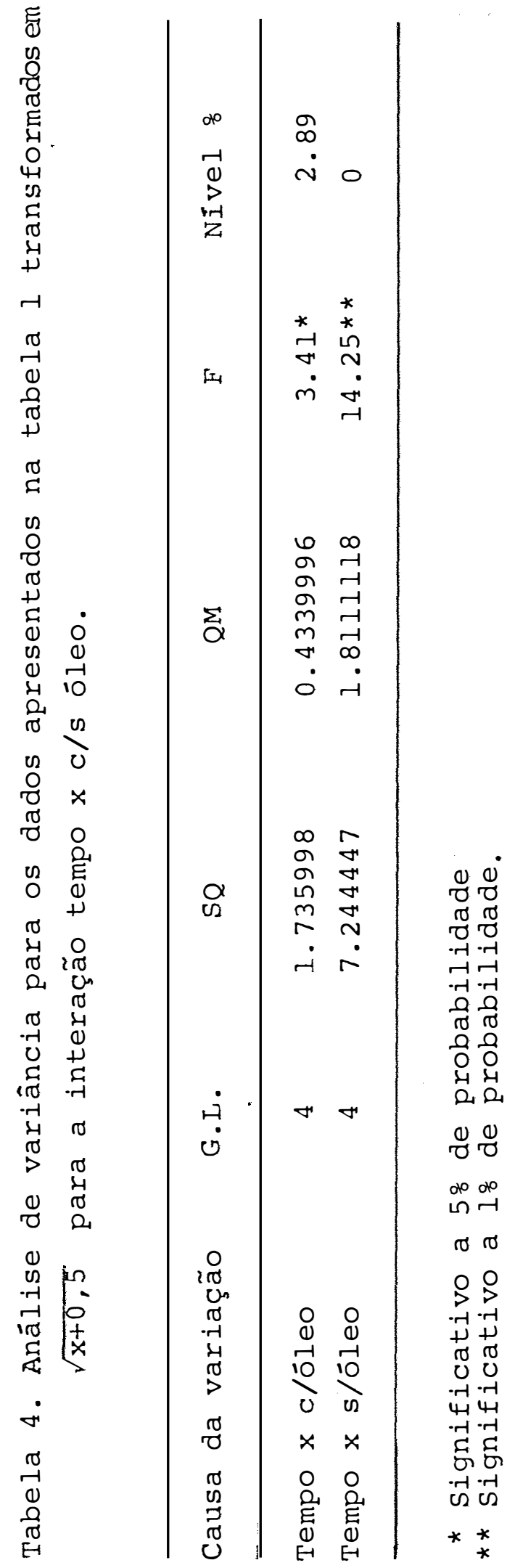


Tabela 5. Teste Tukey para a variável tempo dos dados apresen tados na tabela 1 e transformados em $\sqrt{x+0,5}$. Piraci caba-SP, 1983.

hora $1=1.97306 \mathrm{a} *$
hora $2=1.20330 \mathrm{~b}$
hora $3=1.11130 \mathrm{~b}$
hora $4=0.81636 \mathrm{~b}$
hora $5=0.771816 \mathrm{~b}$

D.M.S. $(5 \%)=0.46505705$

* Médias seguidas da mesma letra não diferem significativamen te a 5\% de probabilidade.

Tabela 6. Teste Tukey para a interação tempo x s/óleo dos dạ dos apresentados na tabela 1 e transformados em $\sqrt{\mathrm{x}+0,5}$

\begin{tabular}{l} 
hora $1=2.37603 \mathrm{a} \star$ \\
hora $2=1.21654 \mathrm{~b}$ \\
hora $3=0.96592 \mathrm{~b}$ \\
hora $4=0.83651 \mathrm{~b}$ \\
hora $5=0.70710 \mathrm{~b}$ \\
\hline D.M.S. (5\%) $=0.757502019$
\end{tabular}

* Médias seguidas pela mesma letra não diferem significativamente a 5\% de probabilidade. 
34.

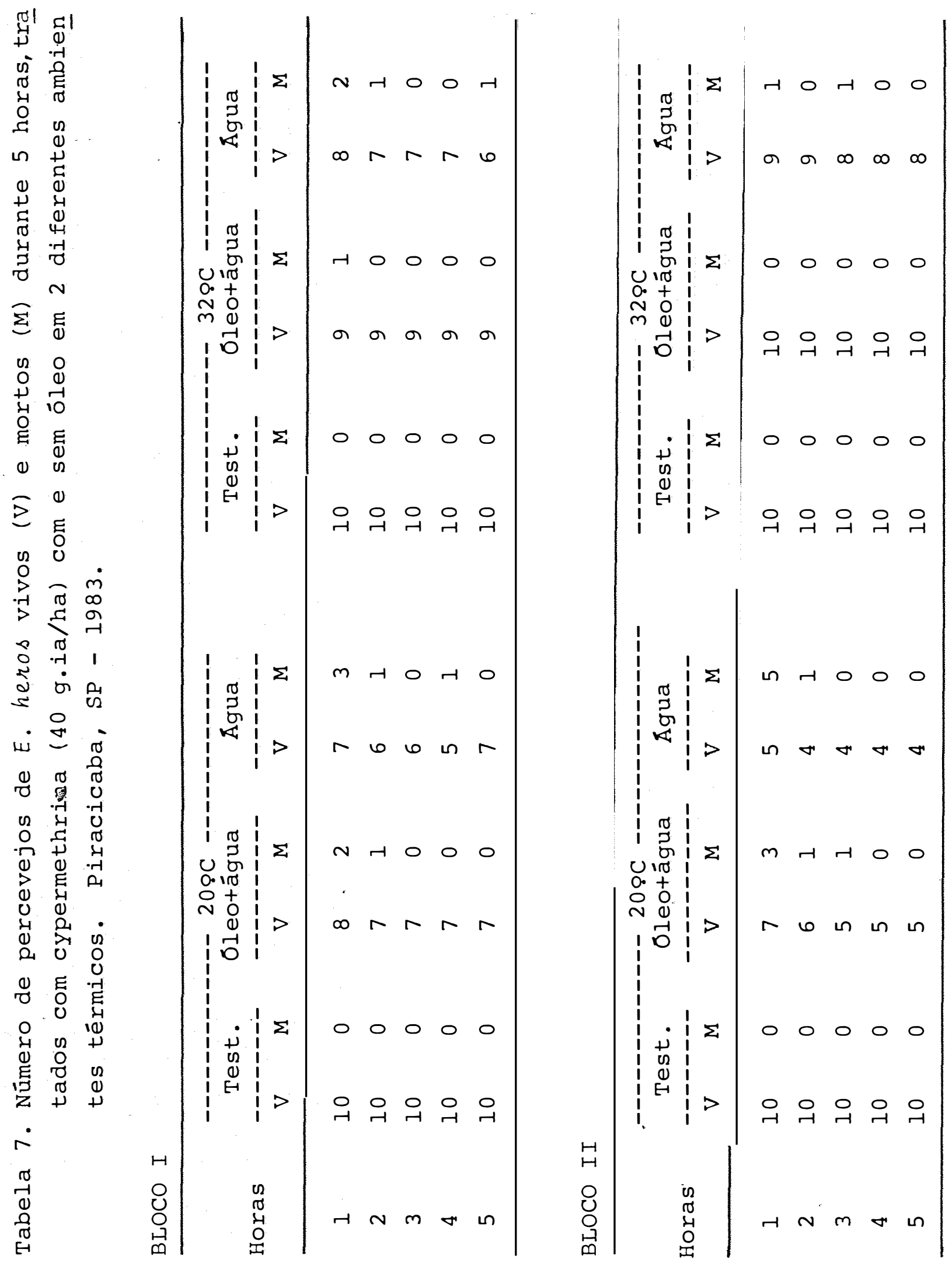




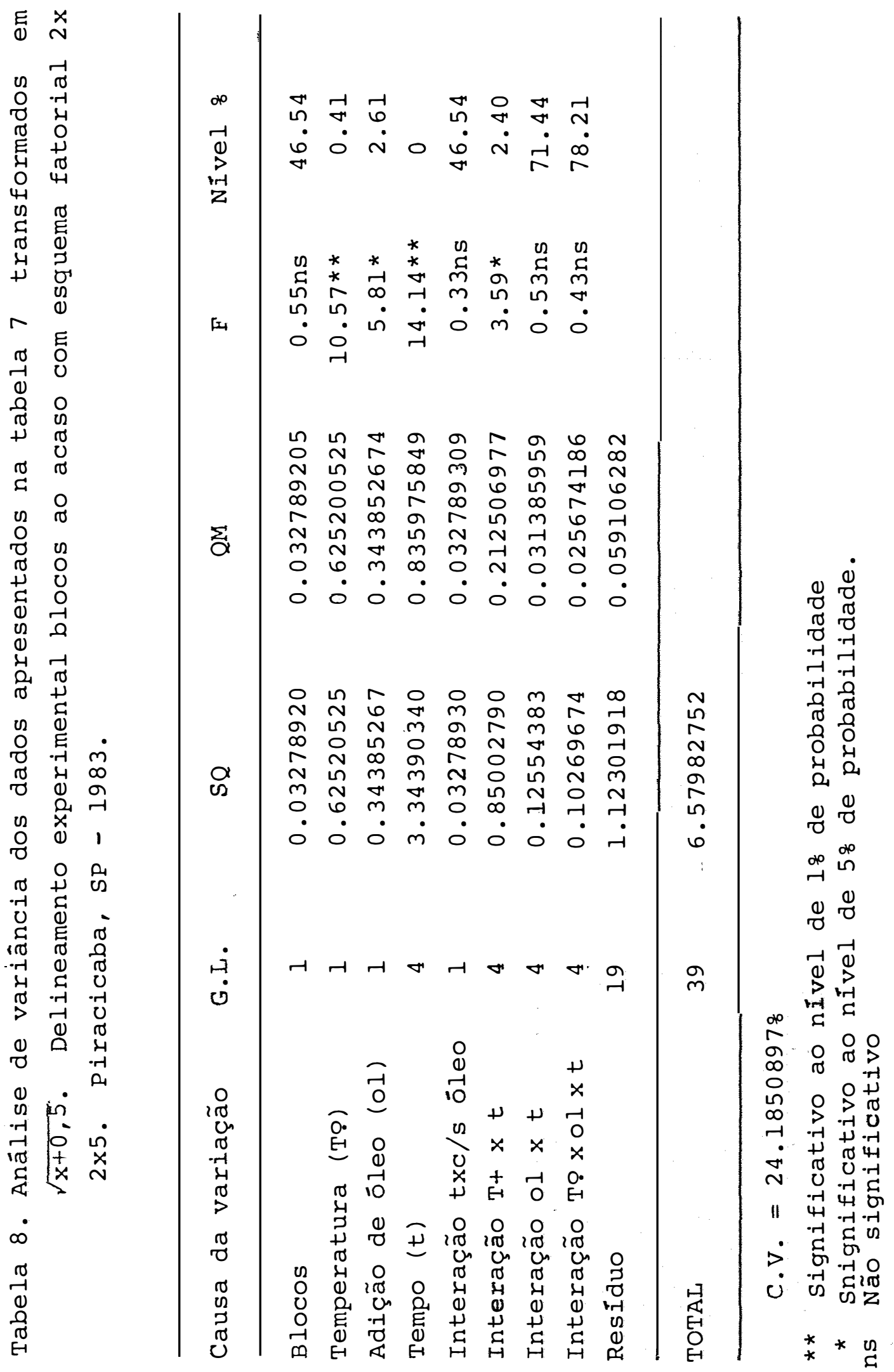


Tabela 9. Teste Tukey para a variável tempo dos dados apresen tados na tabela 7 e transformados em $\sqrt{x+0,5}$. Piracicaba, SP - 1983.

hora $1=1.55071 \mathrm{a}$
hora $2=1.03063 \mathrm{~b}$
hora $3=0.90122 \mathrm{~b}$
hora $4=0.77181 \mathrm{~b}$
hora $5=0.77181 \mathrm{~b}$

D.M.S. $(5 \%)=0.317174424$

* Médias seguidas pela mesma letra não diferem significativamente a 5\% de probabilidade. 
Tabela 10. Teste Tukey para a interação tempo $\mathrm{x}$ temperatura (209C) dos dados apresentados na tabela 7 e transformados em $\sqrt{\mathrm{x}+0,5}$. Piracicaba, SP - 1983 .

hora $1=1.91700 \mathrm{a}$
hora $2=1.22474 \mathrm{~b}$
hora $3=0.96592 \mathrm{~b}$
hora $4=0.83651 \mathrm{~b}$
hora $5=00.77181 \mathrm{~b}$

D.M.S. $(5 \%)=0.516625361$

* Médias seguidas pela mesma letra não diferem significativamente ao nivel Je 5\% de probabilidade.

Tabela 11. Teste Tukey para a interação tempo $x$ s/óleo dos dados apresentados na tabela 7 e transformados em $\sqrt{\mathrm{x}+0,5}$. Piracicaba, SP - 1983 .

hora $1=1.75548 \mathrm{a} *$
hora $2=1.09533 \mathrm{~b}$
hora $3=0.96592 \mathrm{~b}$
hora $4=0.83651 \mathrm{~b}$
hora $5=0.83651 \mathrm{~b}$

D.M.S. (5\%) $=0.516625361$

* Médias seguidas da mesma letra não diferem significativamen te ao nível de 5\% de probabilidade. 
38.
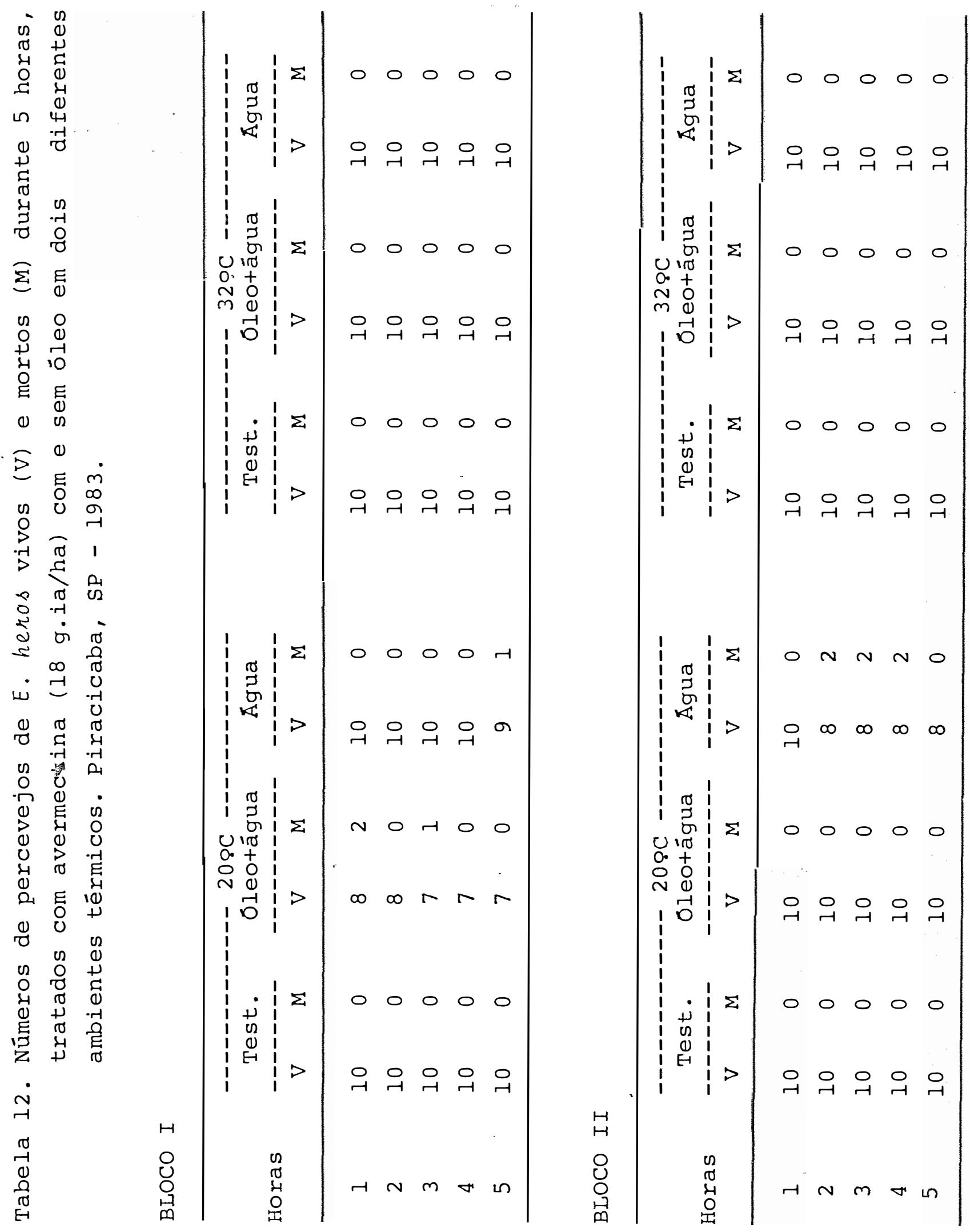


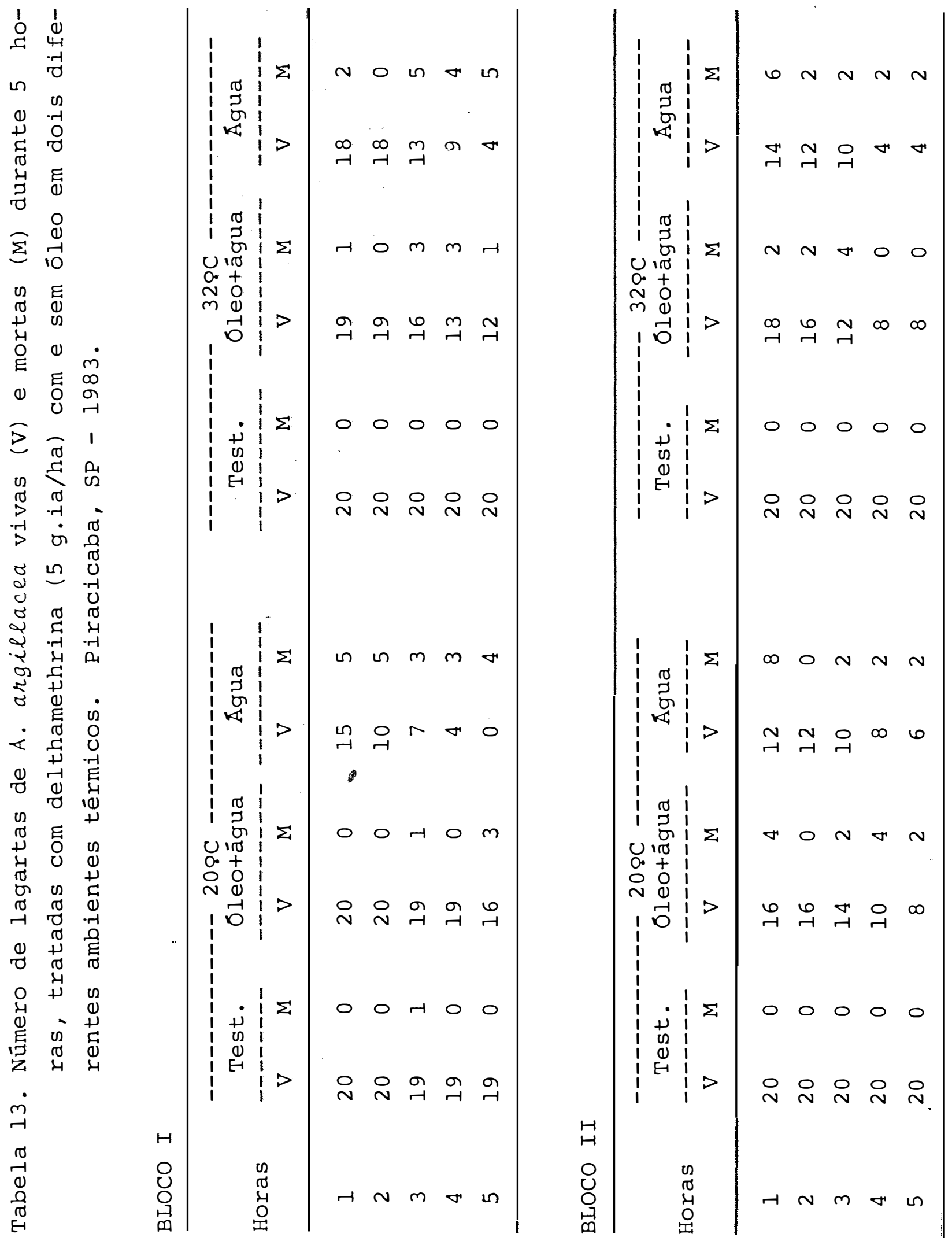


40.

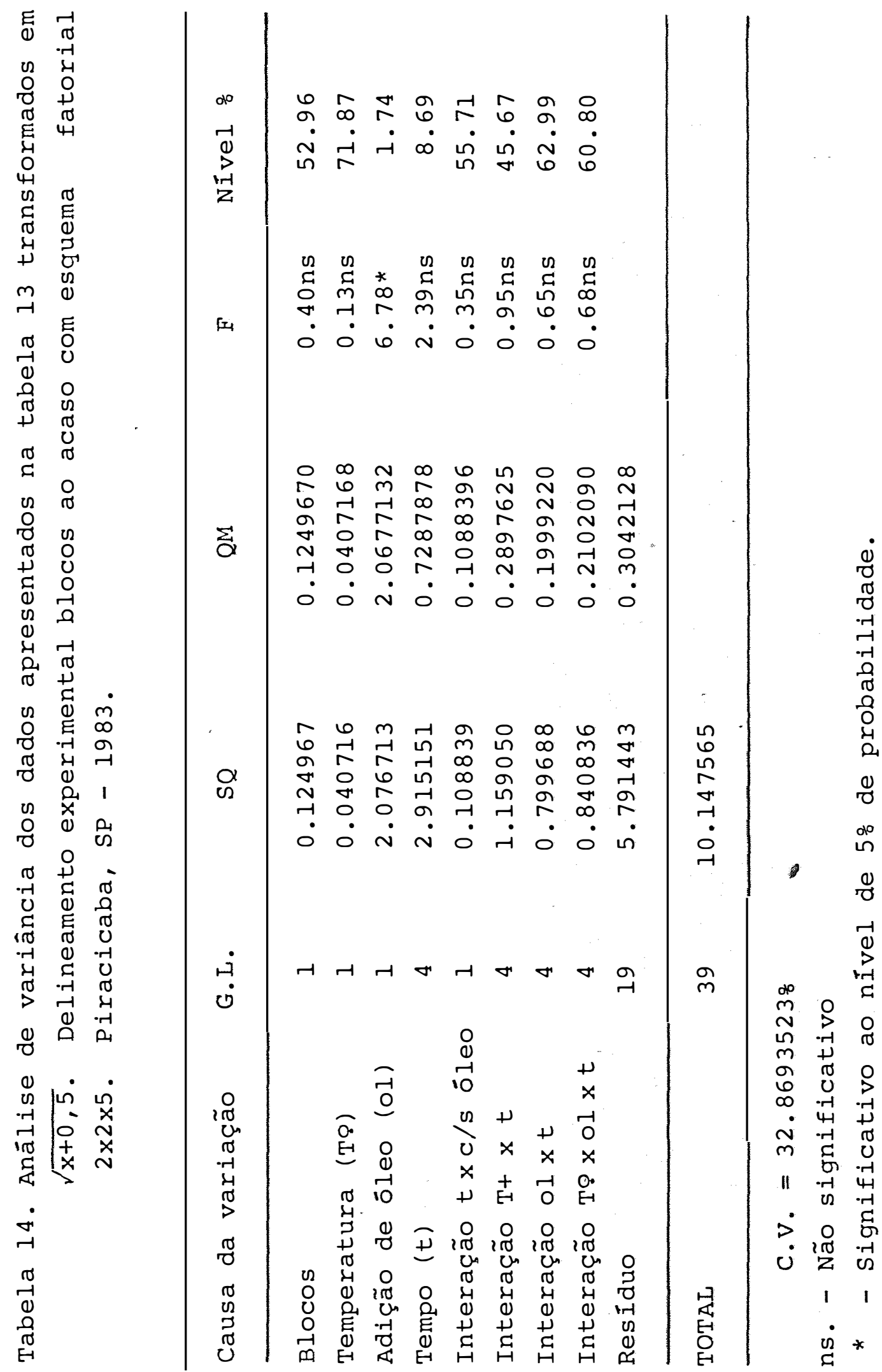




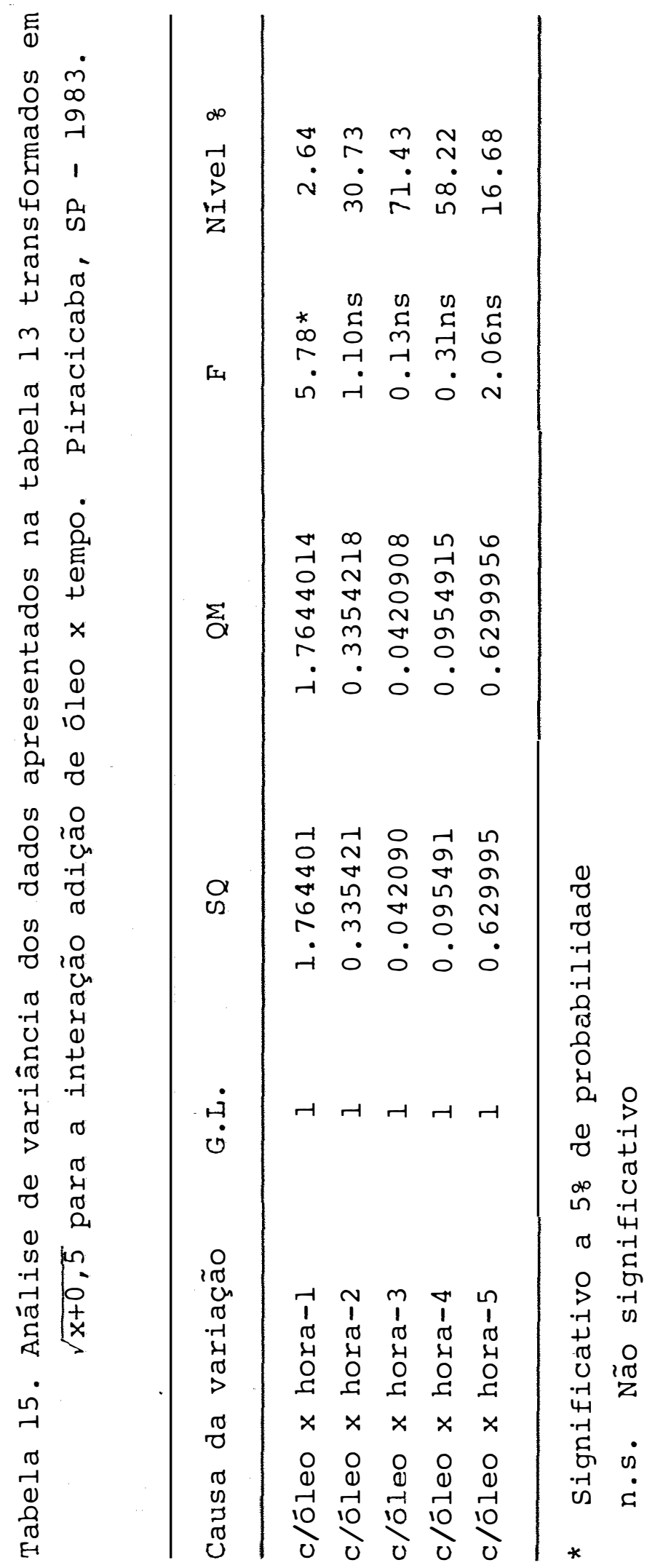


42.

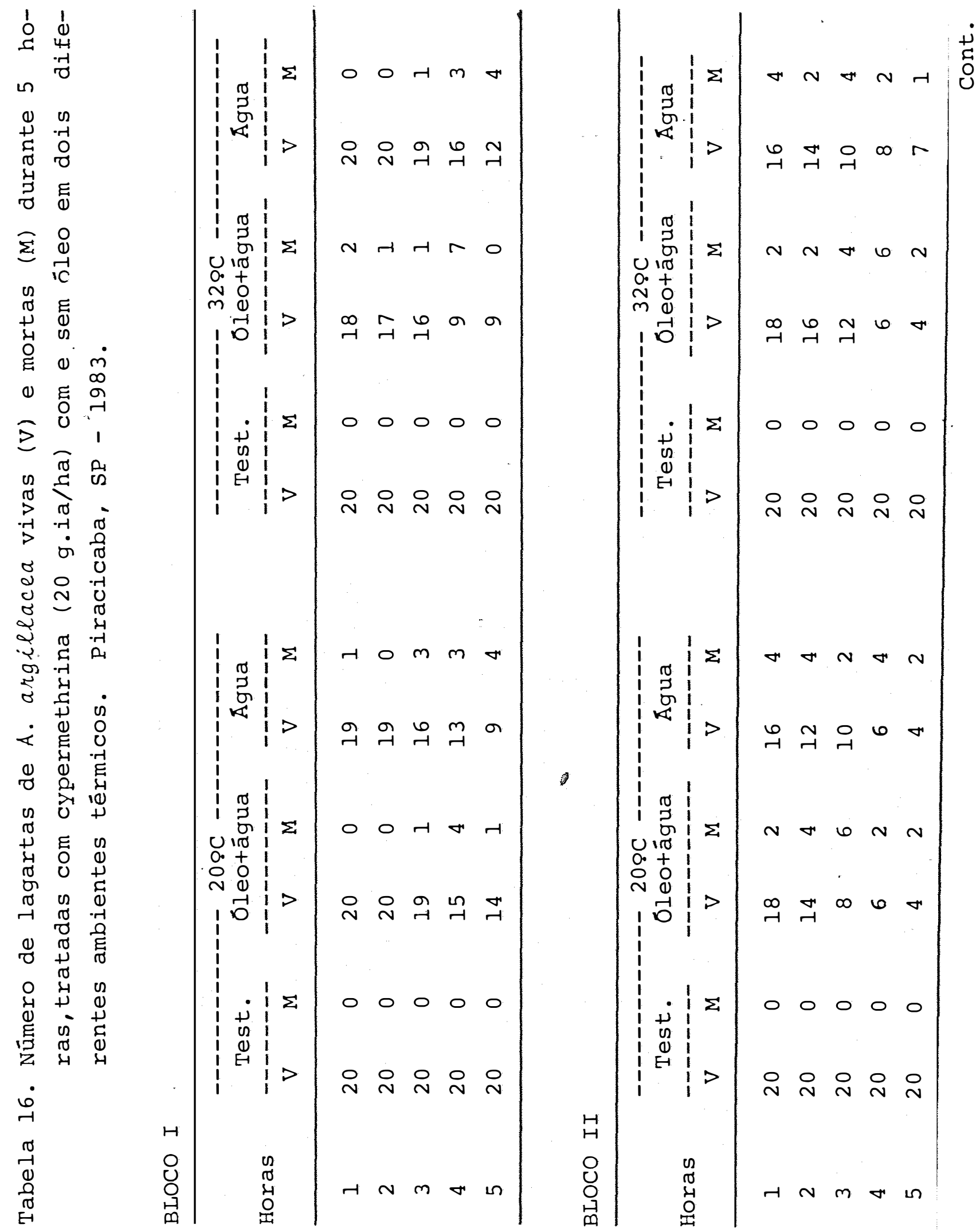


43.

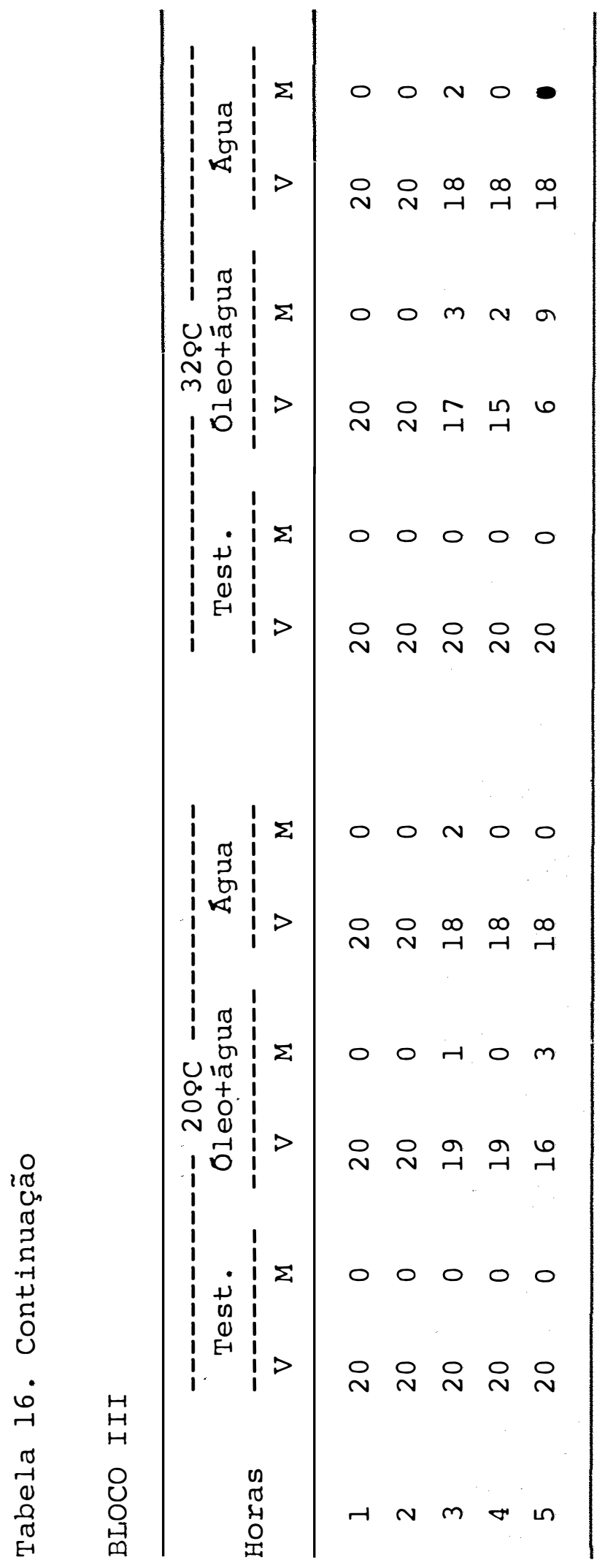




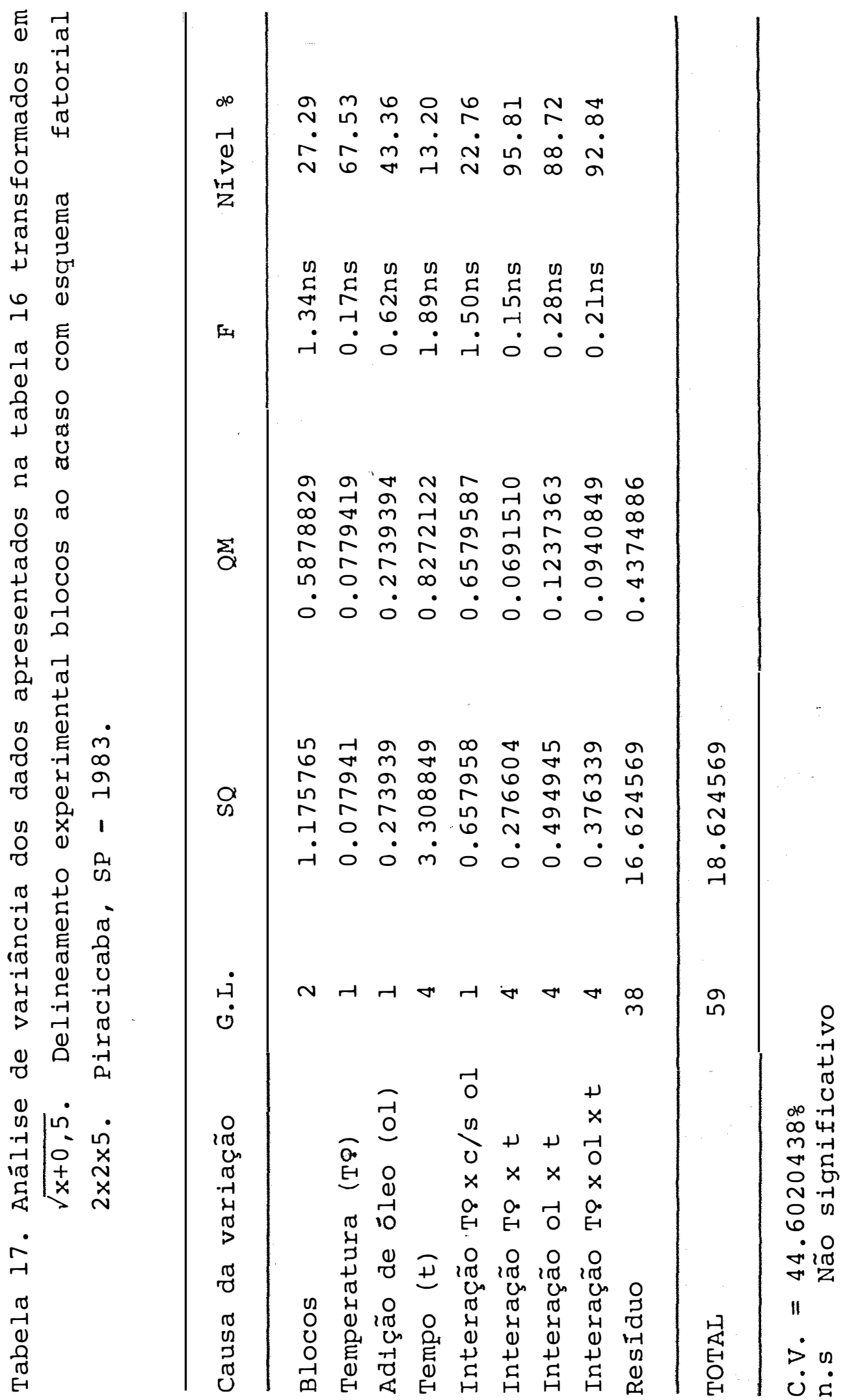




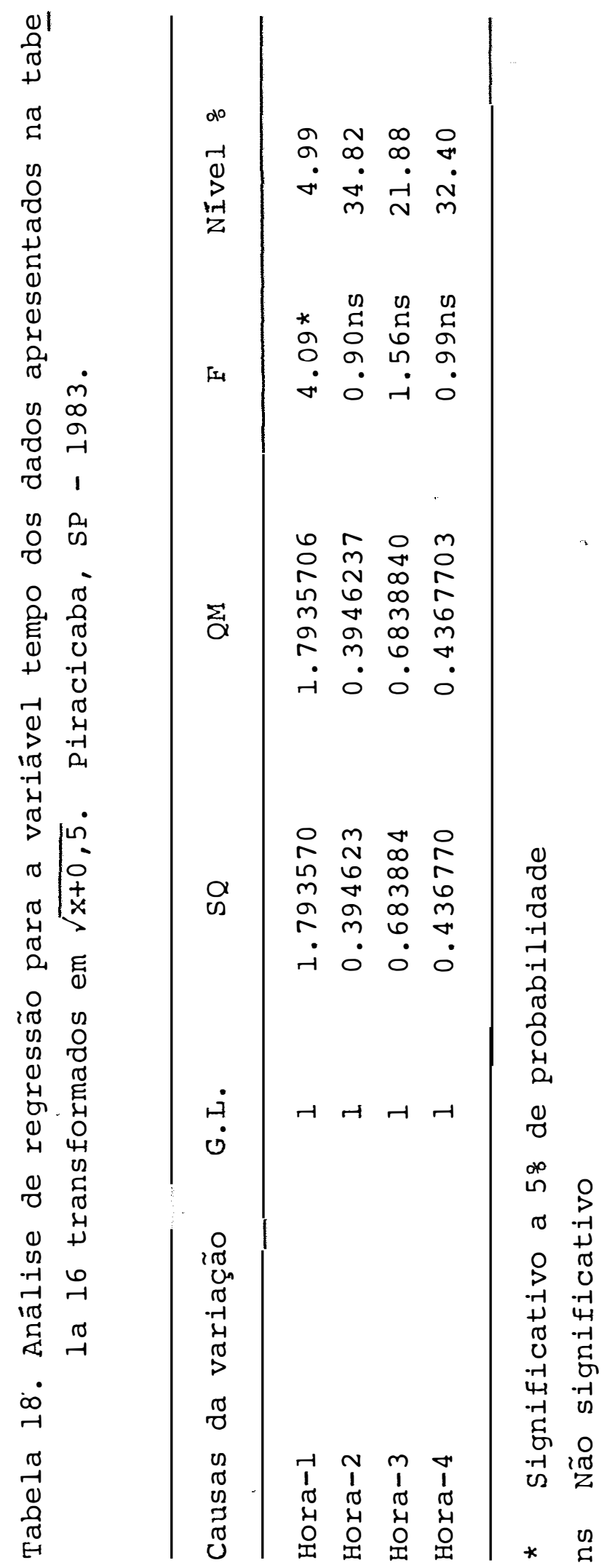


46.

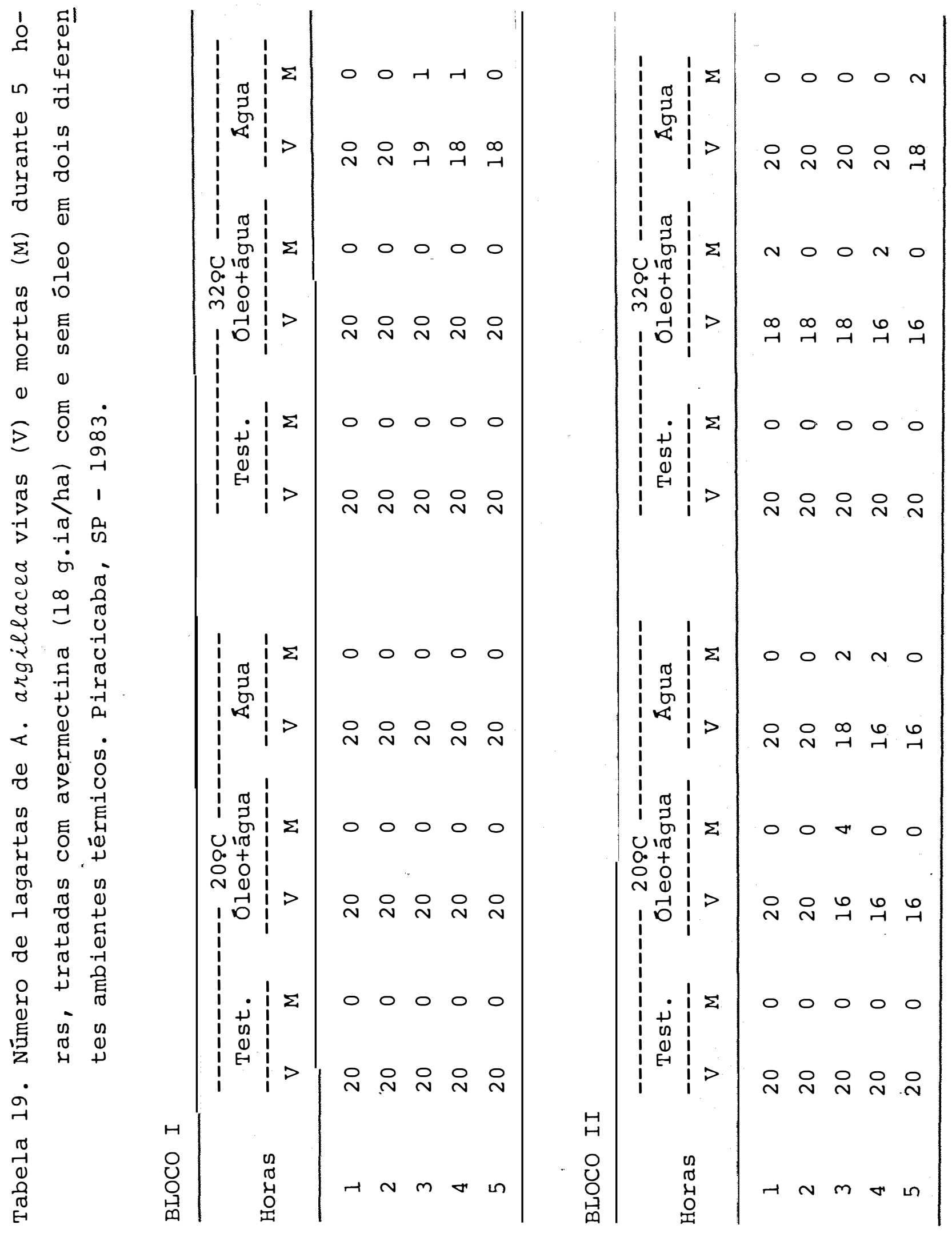




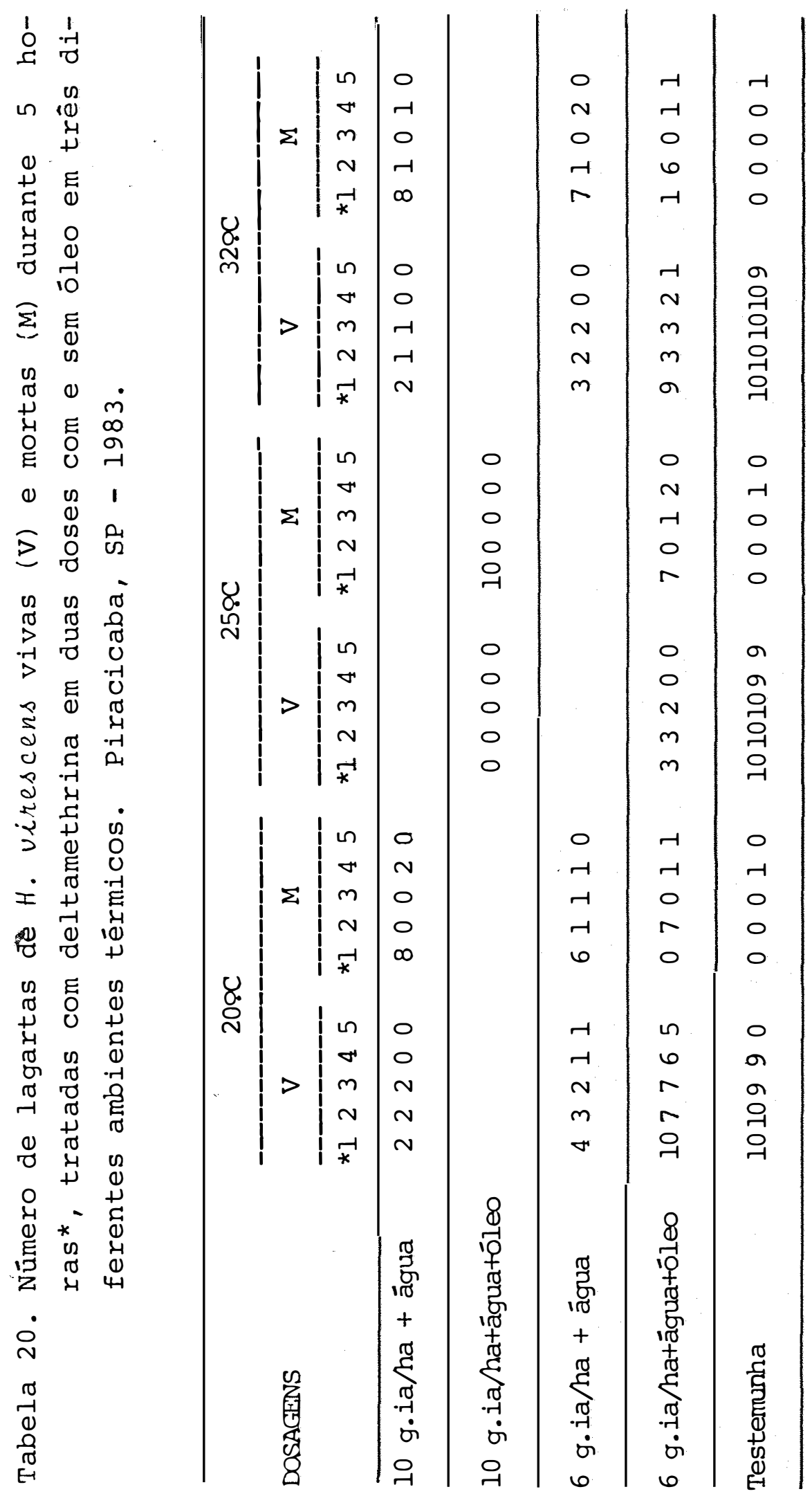


48.

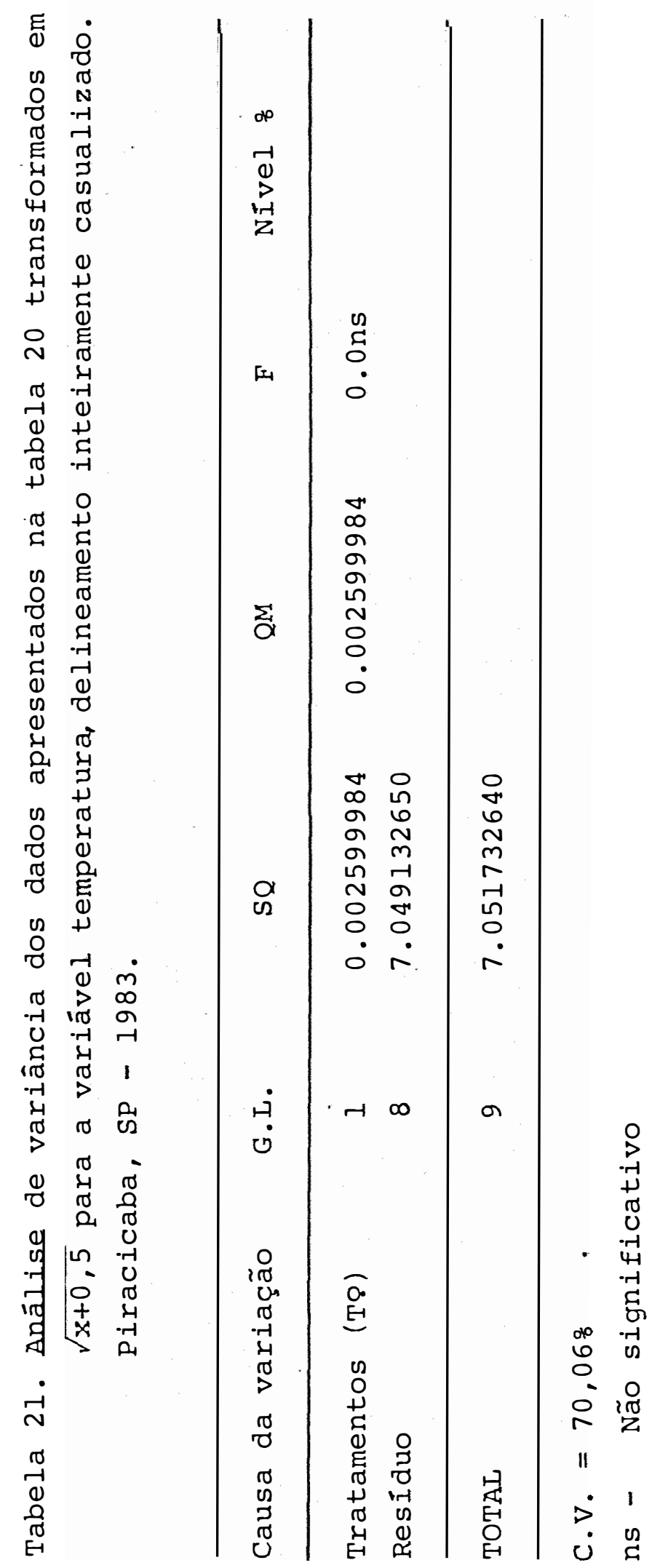


49.

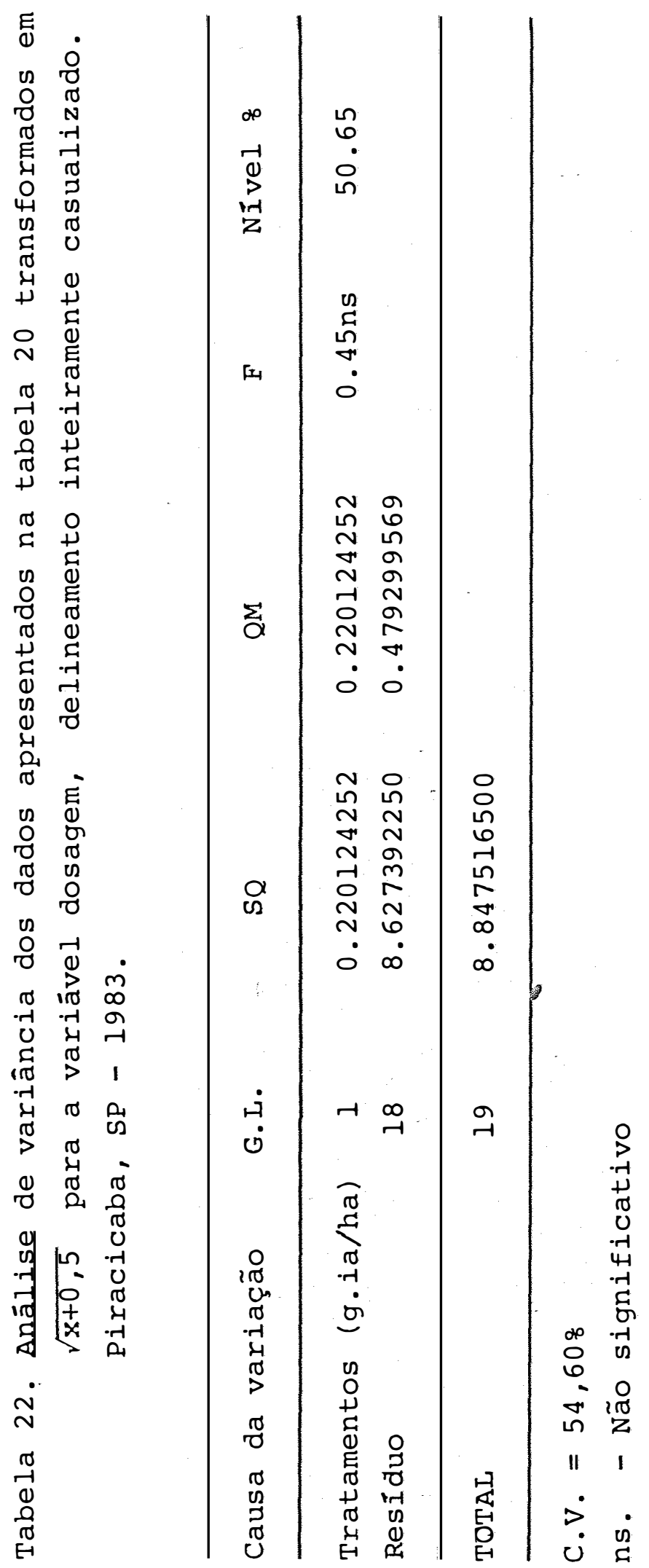


50.

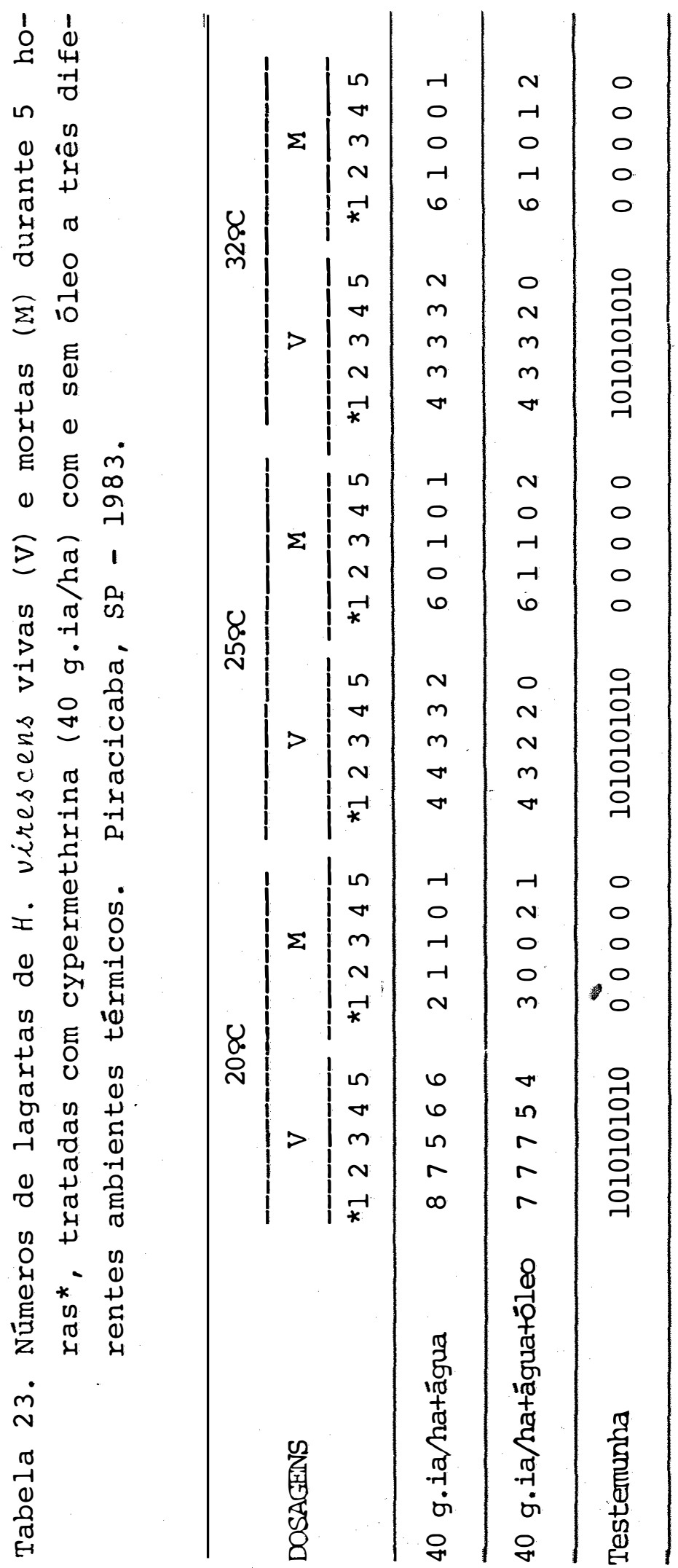




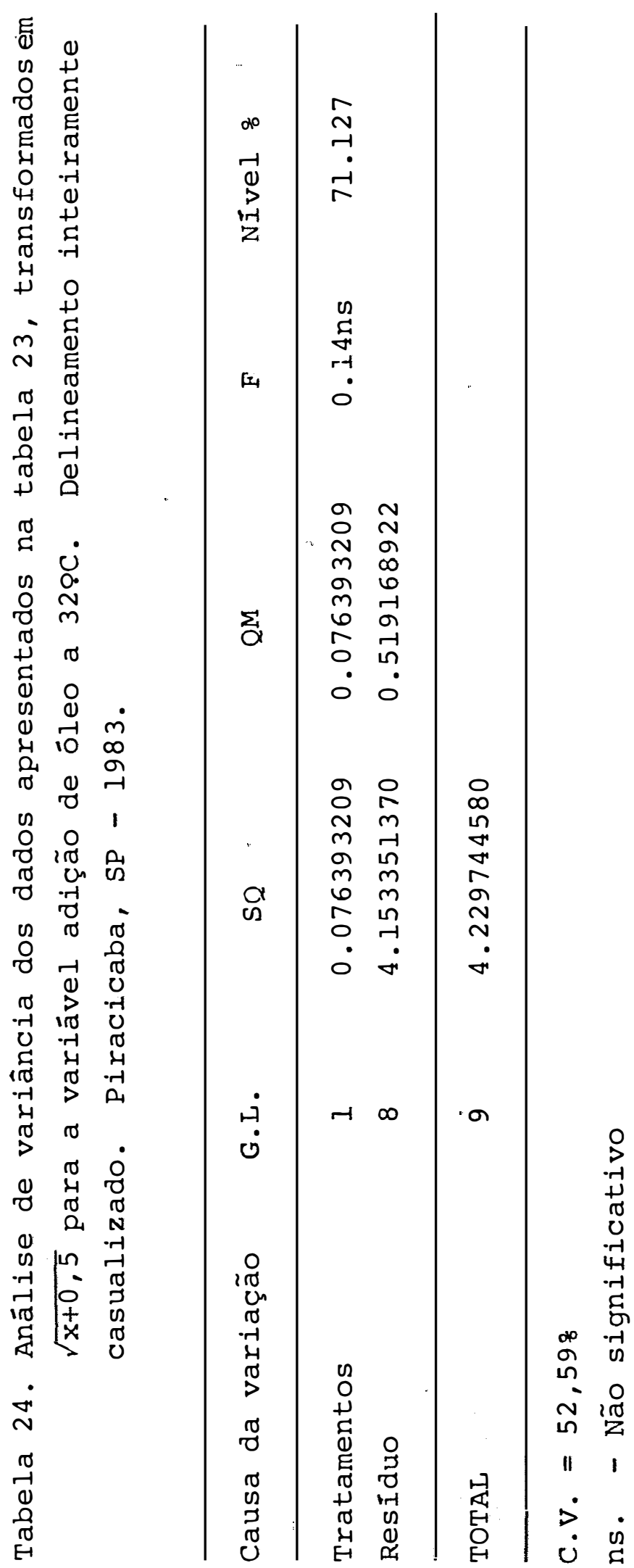




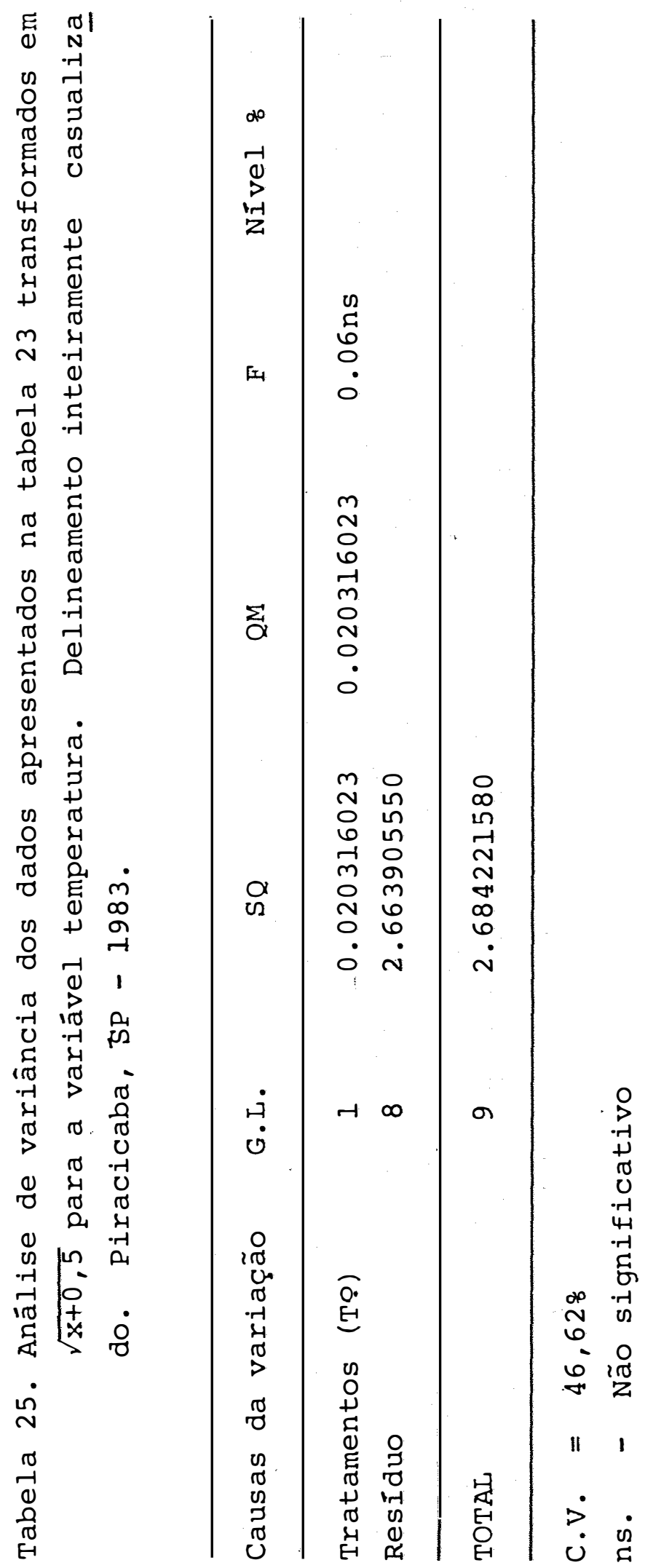




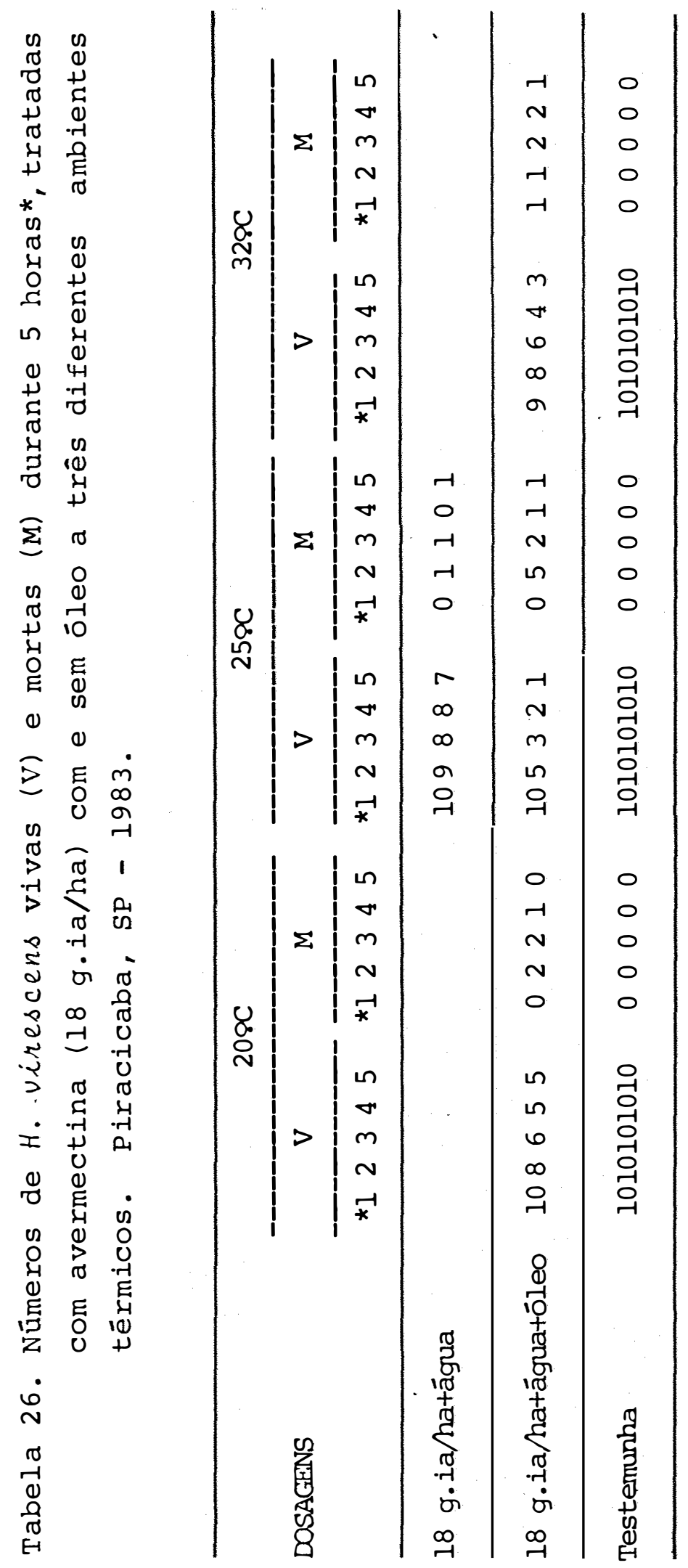


54.

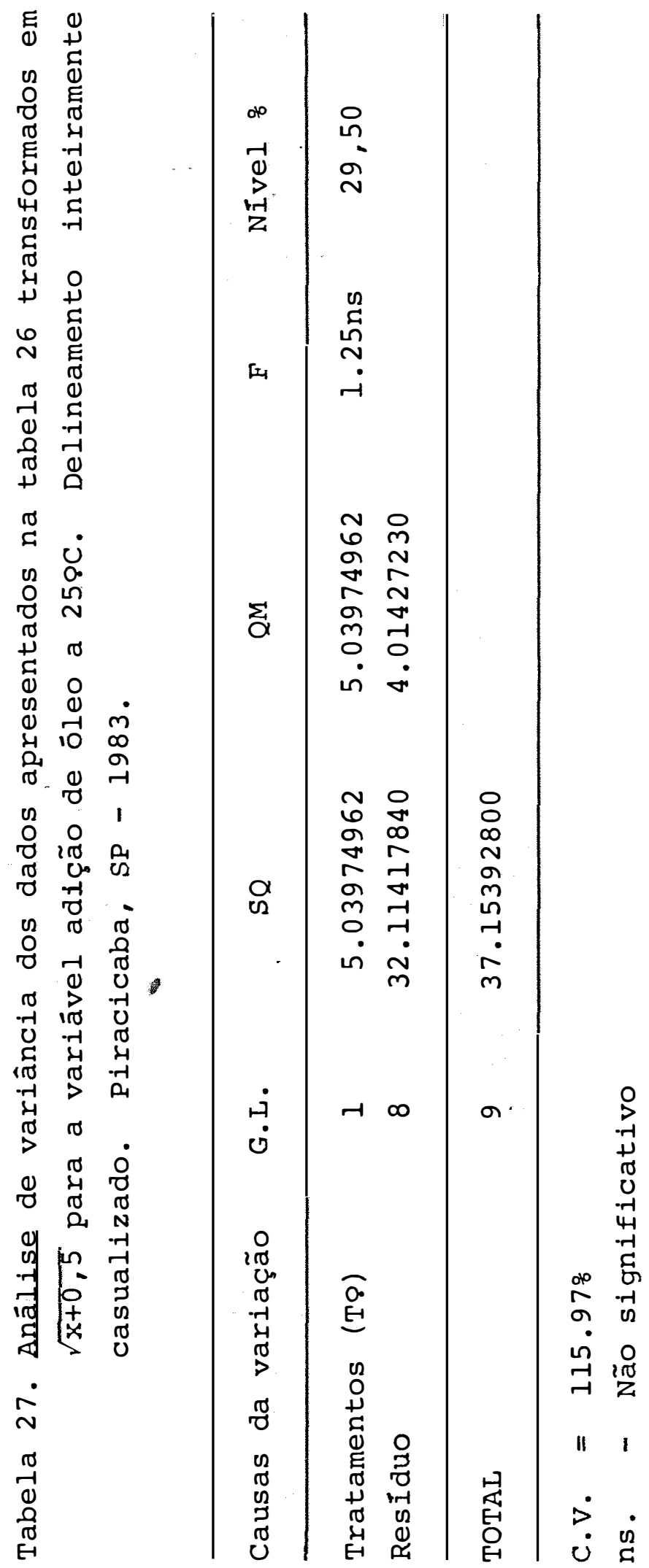




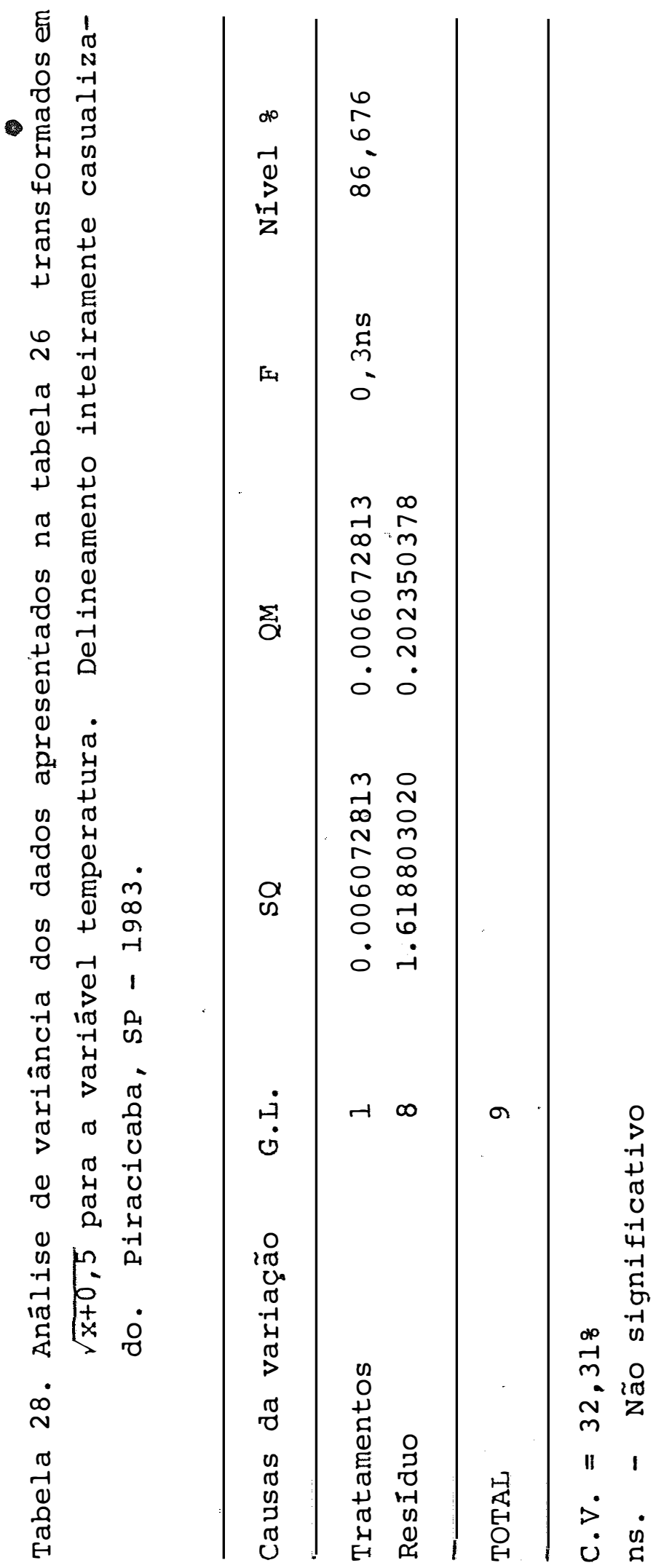

